Revista lus et Praxis, Año 23, No 2, 2017, pp. 79 - 120

ISSN 0717 - 2877

Universidad de Talca - Facultad de Ciencias Jurídicas y Sociales

Traduciendo el discovery al civil law chileno: Su aporte a los procesos de reforma procesal civil

Cristóbal Peña Mardones

Trabajo recibido el 7 de marzo de 2016 y aprobado el 12 de abril de 2017

\title{
Traduciendo el discovery al civil law chileno: Su aporte a los procesos de reforma procesal civil
}

TRANSLATING DiscoverY IN CHILEAN LAW KEY: IT'S CONTRIBUTION TO THE

CIVIL PROCEDURE REFORM PROCESS

\section{Cristóbal Peña Mardones*}

\section{ResumeN}

Los procesos de modernización de la justicia civil en curso de ser implementados en Chile reconocen como características, por una parte, la instauración de un modelo de juzgamiento oral fundado en el principio adversarial, con fuerte injerencia de las partes en su conducción, y por otra, una manifiesta promoción, públicamente alentada, de los sistemas alternativos de solución de conflictos (SARC). La adopción de etapas de revelación temprana de evidencia pertinente (discovery y disclosure) modeladas a partir de la experiencia comparada del common law norteamericano e inglés presenta una serie de efectos que facilitan la promoción de ambas características del nuevo diseño procesal, tornando necesario que se considere la inserción de aquellas en las iniciativas de reforma en curso, de ser puestas en marcha.

\section{ABSTRACT}

The civil justice modernization process currently under implementation in Chile, features, on one hand, the establishment of an adversarial-founded oral trial model in which parts hold a central and relevant role, and on the other, a publicly fostered and openly promoted initiative towards the adoption of Alternative Dispute Resolution (ADR) means. The incorporation of early stages of disclosure of relevant evidence (discovery or disclosure) modelled by the american and british common law experience display a series of positive consequences for both characteristics of the new process design, making it necessary to ponder on the insertion of the aforementioned within the initiatives of reform presently under discussion.

\section{Palabras Clave}

Etapas de revelación temprana de evidencia pertinente, discovery, disclosure, common law, derecho continental, proceso adversarial oral, transparencia, colaboración, simetrías, juicio civil, sistemas alternativos de resolución de conflictos, buena fe, sorpresa ilegítima

KEY WORDS

Stages of early disclosure of relevant evidence, discovery, disclosure, common law, civil law, adversarial oral trial, transparency, colaboration, symmetries, civil trial, alternative dispute resolution means (ADR), good faith, unfair surprise

\footnotetext{
* Abogado. Doctorando en Derecho, Universidad de Talca. Magíster en Tributación, Universidad de Talca. Licenciado en Derecho, P. Universidad Católica de Chile. Correo electrónico: penamardones@ yahoo.com.
} 


\section{Introducción}

El ordenamiento jurídico procesal chileno, desde hace ya más de una década, viene experimentando una serie de profundas reformas estructurales, enmarcadas en el contexto de iniciativas que, en su conjunto, han sido dadas en llamar como de "modernización de la justicia", la última de las cuales ha sido la de la justicia civil. Dichas iniciativas presentan, en su gran mayoría, en lo que interesa a las líneas que siguen, dos características bien definidas: por una parte, muestran una tendencia marcada hacia la puesta en valor de los sistemas alternativos de resolución de conflictos (SARC o ADR) de amplio alcance, incluso a través de herramientas que, aún ligadas a salidas heterónomas y radicadas en el aparato público, simplifican de manera importante esta última solución, atendiendo a una tendencia generalizada en pos de entregar una respuesta de mejor calidad a la solución pacífica de los conflictos de los usuarios del sistema, que les resulte más cercana, simple y eficaz y que, al mismo tiempo, como una externalidad valorable, redunde en un beneficio para el sistema estatal de justicia (de ahí la denominación SARC) representado por la descongestión del mismo y que excede, en realidad, al Poder Judicial como lo conocemos hoy'.

Los afectados por estos procesos, por su parte, abandonan ya la posición de los justiciables (como simples sujetos pasivos de la resolución heterónoma del conflicto jurídicamente relevante) para ocupar el rol de titulares del derecho fundamental al acceso a la justicia ${ }^{2}$, aun cuando ello no se traduzca necesariamente en el ingreso al sistema judicial propiamente tal ${ }^{3}$. La calidad de la respuesta que ofrece el recurso a los SARC resta todavía, empero, por ser evaluada, pero dicho análisis debe ser presidido por la consideración que los ADR reclaman para sí, como se dijo, las ventajas de resultar más cercanas a la naturaleza del diferendo y a las expectativas de las partes ${ }^{4}$.

Por otra parte, en tanto, es necesario reconocer que las modernizaciones a la justicia civil en comento han apuntado en gran medida, con mayor o menor énfasis, hacia la estructuración de procedimientos jurisdiccionales en los que impera el principio adversarial ${ }^{5}$, preponderante en los modelos de juicio oral (aun en los contextos en que esta salida se presente, en realidad,

\footnotetext{
1 Palomo y Delgado (2016), p. 90.

2 TwINING (1993), p. 380.

3 Palomo y Delgado (2016), p. 90.

4 Summers (2011), p. 22.

5 "Contienda o disputa que se desarrolla como el compromiso de dos adversarios ante un Juez relativamente pasivo que debe dictar un veredicto como deber primordial". DAMASKA (2010), p. 13.
} 
como de ultima ratio), conservando porciones relevantes de la iniciativa procesal en general, y de producción de la prueba en particular, en poder de las propias partes intervinientes, reservando al juez, eso sí, el fundamental rol de dirección y orden del proceso y una injerencia más o menos modulada en función del papel primeramente enunciado, sin perjuicio de aquella que le es tradicionalmente propia, consistente en la resolución del conflicto mediante la sentencia adjudicativa heterónoma.

En torno a este último punto, resulta preciso tomar debida nota acerca del lugar preponderante que a la ampliación de los poderes del juez, aun discrecionales, le ha reconocido la evolución de los ordenamientos norteamericano e inglés, en los que este estudio se basa, a lo largo del siglo $X X^{6}$ y dentro de ello, muy especialmente, el debate en torno a la legitimidad de entregar al fallador estatal civil un rol activo no solo en la promoción de los SARC, sino que aun en el control de la manera en que las partes estructuran por sí, o asistidas por terceros, una solución de compromiso a su conflicto, pues una vez que desaparece el conflicto jurídicamente relevante, se cuestiona si al juez en particular y al aparato público en general, le cabe una intervención legítima7.

Aun considerando las notas previas, hacia fines de la década del 2000, del total de las demandas que llegan a ser judicializadas en el medio estadounidense, casi el 50\% terminan siendo resueltas en sede de mediación (fuertemente motivada por el propio tribunal) y aun en segunda instancia, el porcentaje alcanza cifras cercanas al $40 \%{ }^{8}$, estadística que no contempla, tal vez por la dificultad metodológica que lleva envuelta, la enorme cantidad de asuntos litigiosos que derechamente nunca entran al sistema de juzgamiento estatal heterónomo.

Los proyectos que se han propuesto en reforma de la justicia civil en nuestro medio, en lo que interesan a estas páginas, reconocen, con toda nitidez, estos dos rasgos característicos ${ }^{9}$, de manera que resulta preciso y pertinente

${ }^{6}$ Chase (2005), p. 119.

7 ReSNIK (1986), p. 554.

${ }^{8}$ Barona (2010), p. 472.

${ }^{9}$ Ya el proyecto original de nuevo C.P.C. de mayo de 2009 declaraba: "Se requiere de un Nuevo Sistema de Solución de los Conflictos Civiles y Comerciales, que aleje la idea del enjuiciamiento civil como opción única, integrando una amplia visión de los diversos mecanismos alternativos de solución de conflictos existentes, tanto judiciales como extrajudiciales, siempre mediante simples y desformalizadas vías que permitan un real y efectivo acceso de las personas a la justicia". (Mensaje, p. 7), en tanto que declara, en relación con la oralidad ( $y$, por tanto, de la adversarialidad) y rol del juez que: "Como es dable apreciar, el rol que juega el juez en este procedimiento es, sin lugar a duda, un rol activo. Es que no es concebible un procedimiento oral eficiente, en la resolución de 
plantearse, a su respecto, la problemática que representa el diseño de instituciones adecuadas y funcionales a la mejor implementación de dichas facetas y que, por lo tanto, tengan el potencial de promover, por una parte, un uso intensivo de los SARC desde el interior del desarrollo del proceso civil o aun en sus etapas más tempranas, con mayor o menor intervención del juez y, a la vez, presten utilidad para configurar un adversarial oral simple, transparente y equitativo, pues: "Un buen procedimiento no es aquel que lleva todo asunto a juicio, sino aquel que permite discriminar lo que merece ser llevado a juicio"10.

En otras palabras, se pretende dilucidar de qué manera insertan en un proceso adversarial de corte oral, como aquel propuesto entre nosotros, aquellas herramientas que, representando un valor intrínseco al propio proceso de adjudicación, importen a la vez una motivación para los interesados a fin de que estos recurran a soluciones diversas del juzgamiento estatal tradicional; definir conceptualmente qué herramientas son estas y, en definitiva, de qué manera el uso de las mismas se traduce en la apertura de ejes orientados a la obtención de ambos objetivos.

En respuesta a las cuestiones recién planteadas, las líneas que siguen se orientan a sostener que una determinada herramienta procesal, que representa una componente esencial, modélica al proceso civil adversarial oral imperante en los Estados Unidos de Norteamérica e Inglaterra, en menor medida, consistente en las así llamadas instancias de discovery (descubrimiento) y disclosure (revelación), importa consecuencias de inestimable valor para los aspectos ya enunciados de los procesos de modernización de la justicia.

En efecto, estas entidades que, en síntesis, obligan a los litigantes, espontáneamente primero o mediante la intervención del aparato judicial más tarde, a revelar, en las etapas más tempranas del procedimiento, los fundamentos del material probatorio en que sustentan sus pretensiones, poniendo a disposición de su contradictor el mismo para su examen, facilitan, por una parte, el acceso a una administración estatal de justicia (heterónoma) exenta de asimetrías de información que quebranten, en definitiva, tanto la igualdad de armas como la colaboración exigible a los litigantes que se ve comprometida gravemente con la así llamada "sorpresa injusta" (unfair surprise) y, por otra, en un rol progresivamente relevante en los estatutos en estudio, representan un poderoso incentivo para que las partes se representen seria y fundadamente la factibilidad de recurrir a las más variadas formas de SARC, algunas

un conflicto privado, sin la acción potente del juzgador que asuma directamente el rol de dirección del proceso y represente al órgano público frente a la acción de las partes". (Mensaje, p. 9).

10 VIAL (2006), p. 720. 
de las cuales ni siquiera importan una renuncia al aparato público, tenido por muchos, y particularmente en el contexto de los sistemas continentales de administración de justicia o civil law como el chileno, como el administrador de justicia por antonomasia ${ }^{11}$, indisolublemente unido a la garantía de acceso a la justicia ${ }^{12}$. De todo ello se sigue que se proponga por lo tanto, en definitiva, la pertinencia de considerar la extrapolación de herramientas de este tipo hacia nuestros procesos de reforma al proceso civil en aras de los objetivos que estas se han trazado.

Se buscará en los párrafos que siguen, en consonancia con la hipótesis que los sustenta, dar a estas instituciones, características del common law nortamericano e inglés, una lectura desde la perspectiva de los procesos de modernización de la justicia civil en nuestro medio de inspiración continental y, poniendo especial énfasis en su poderosa vinculación tanto con los SARC como con los principios que permiten el mejor funcionamiento de los procedimientos adversariales, demostrar que existen fundados motivos para darles cabida en aquellos.

Se expondrá a continuación, siguiendo el orden de ideas ya enunciado, una lectura conceptual, sobre la base de las nociones procesales chilenas, de las instituciones objeto de este estudio, para proceder seguidamente a analizar la forma en que estas se implantan y funcionan en los ordenamientos materia de esta investigación. Seguidamente, como una cuestión central, se analizará cuáles son las consecuencias, funcionales a los objetivos ya anunciados, que se pueden describir a partir de su implantación para, a continuación, examinar los puntos de conflicto que su eventual inserción en nuestro medio podría representar, cerrando, en fin, con algunas conclusiones que evidenciarán que la adopción de este tipo de instituciones, modeladas de acuerdo a la estructura del proceso civil chileno reformado, representará consecuencias de un valor tal a los mismos, que aconsejará consultar su adopción entre nosotros.

\section{Desentrañando los enigmáticos discovery \& disclosure en clave del civil law chileno}

\subsection{La experiencia estadounidense en materia de discovery y disclosure}

El obligado estudio, desde una perspectiva nacional, de la experiencia comparada recogida a partir de los estatutos norteamericanos, e ingleses, en

\footnotetext{
11 Subrin (2002), p. 301.

12 Barona (2011), p. 186.
} 
menor medida ${ }^{13}$, tenidos como paradigmas de los ADR múltiples, ágiles y de fácil acceso, aun a partir de un propio proceso civil ${ }^{14}$, que contempla etapas de revelación temprana de evidencia pertinente (ERTEP) en fases preliminares del conflicto, enseña que ello ha acarreado efectos empíricamente demostrables en dichos medios: la tasa de judicialización ${ }^{15}$ de los conflictos se ve notablemente disminuida; las soluciones alcanzadas acomodan de mejor manera a los principios de colaboración y buena fe contractual que inspiran el legítimo ejercicio de una amplia autonomía negocial ${ }^{16} \mathrm{y}$, adicionalmente, descomprime el aparato judicial estatal, al sacar del ámbito público áreas importantes de conflictos de todo tipo ${ }^{17}$, que terminan siendo resueltos por las propias partes (mediante soluciones interpares, como la mediación o la conciliación), por justicia pactada (que contempla alternativas supra pares, en forma del amplio espectro de los arbitrajes) o incluso por fórmulas de justicia estatal simplificadas (summary pleadings, demurrers, dissmisals) a partir precisamente de la información que emana del desarrollo de estas instancias que, comprobadamente, representan una motivación importante para recurrir a unos ADR que ofrecen un amplio espectro de salidas al conflicto $^{18}$.

El efecto recién reseñado perfila así, con su desarrollo, el Ilamado modelo del multidoor court room. De hecho, resultará interesante y particularmente revelador destacar que este fenómeno ha dado lugar a que una parte importante de la dogmática estadounidense se haya abocado a efectuar una modelación incluso aritmética del sistema sobre la base de las probabilidades de éxito en una negociación dependiendo de cuán amplia, sólida y pertinente resulte la información revelada u obtenida en las ERTEP ${ }^{19}$, en pos de mejorar la calidad de la solución que los ADR ofrecen a partir de este punto, esto es, en forma de salidas de compromiso por sobre la tradicional respuesta estatal de adjudicación, que se posterga, aun institucionalmente, a favor de las primeras ${ }^{20}$.

\footnotetext{
${ }^{13}$ Esto hasta la reforma procesal de las Civil Procedure Rules de 1998 (CPR) que acogen relevantes ampliaciones al rango de acción del discovery, armonizadas con una expansión de las facultades del juez civil. Así en ZuCKERMAN (2005), p. 145.

14 Mullerat (2002), p. 54.

15 Entendido este como la demanda por acceso a la justicia estatal, heterónoma, las estadísticas hablan de tasas de judicialización del $2 \%$ al $4 \%$ y aun dentro de ellos, con proporciones relevantes de soluciones autocompositivas. SUBRIN (2002), p. 315.

16 "Miracle medicine" en decir de los "practicioners". Summers (2011), p. 25.

17 Barona (2010), p. 457.

18 Mullerat (2002), pp. 48 y 56.

19 Por todos: Farmer y PeCorino (2014), p. 241.

${ }^{20}$ RESNIK (1986), p. 534.
} 
De esta forma, las instituciones en referencia (fundamentalmente disclosure y discovery), correctamente emplazadas en etapas prejudiciales (pre-trial) o incluso en una suerte de antejuicio ${ }^{21}$, tendrán como favorable efecto, amén de los que resultan procesalmente propios a sus finalidades (consistentes en promover la transparencia de las pruebas de las partes, eliminar asimetrías de información que atenten contra la igualdad de armas y en adquirir medios de convicción útiles al litigante ${ }^{22}$ ), el importar un incentivo para que las partes, en paralelo, consideren seria y fundadamente la adopción, en etapas tempranas del conflicto, de diversas fórmulas de $\mathrm{SARC}^{23}$, funcionales a sus intereses en conflicto $^{24}$. Tan relevante es el rol que desempeña esta instancia al interior del proceso civil estadounidense, que este efecto ha sido instituido ya, de manera expresa, como una de las finalidades de la etapa en que se insertan estos mecanismos ${ }^{25} y$, de hecho, tan profunda es la penetración de este tipo de instituciones en los ordenamientos del common law y, en particular, en el norteamericano, que ha llegado a ser entendido en ese medio como una parte sustancial de la garantía al debido proceso ${ }^{26}$, la que ocupa ya un lugar por completo inseparable de la litigación civil27.

La institución del discovery, como se conoce hoy en el ordenamiento estadounidense, data de 1938, con la dictación de las Federal Rules of Civil Procedure y reconocidamente alcanzó su auge en la década de los 70 del siglo $X X$, con sucesivas modificaciones a dicho cuerpo legal. A contar de los años 80, sin embargo, se comenzó a vivir un progresivo proceso de racionalización de la institución, caracterizada por la búsqueda de lo que se denomina una adecuada "proporcionalización" de la misma en relación con la relevancia del litigio. La más importante de las reformas, sin embargo, que data de 1993, tuvo como efecto indeseado la así llamada "balcanización" del discovery, al autorizar a las judicaturas estatales a adoptar con reservas (opt-out) las nuevas instituciones relativas al disclosure, o revelación autónoma de evidencia (cuya inclusión era el objetivo de los reformadores de 1993), al extremo que uno

\footnotetext{
21 Mullerat (2002), p. 57.

22 Hazard y Taruffo (2006), p. 129.

23 Duce, Marín y Riego (2008), pp. 52-53.

24 Hazard y Taruffo (2006), p. 138.

25 Gilsanz (2010), p. 100.

26 SUBRIN (2002), p. 307.

27 SUBRIN (2002), p. 312.
} 
de los objetivos de las nuevas tendencias reformistas Ilama precisamente a una unificación de los estatutos ${ }^{28}$.

En definitiva, tras superar no pocas voces disonantes que se alzaban en contra de ello, se ha sancionado una nueva reforma en los Estados Unidos, vigente a contar de diciembre de 2015, que otorga un rol más activo al juez civil en la proporcionalización del alcance y envergadura del proceso de discovery como un todo, en relación con la relevancia de la controversia, modificación que, de paso, terminó por demostrar, con la evidencia tangible de la inspiración en ordenamientos continentales, lo acertado del enfoque comparado de Mirjian Damaska y de la hibridización de los sistemas que, por lo mismo, exhibe interesantes resultados ${ }^{29}$, posibilitando su lectura como una forma de "legal transplant".

El favorable efecto que, de acuerdo a la experiencia comparada en los Estados Unidos ${ }^{30}$, produce la adopción de las ERTEP y la ya hoy extendida convicción, imperante en la dogmática más autorizada, en torno a la acuciante necesidad de su inclusión en la base de cualquier contexto de resolución de conflictos en que imperen nociones de adversarialidad y oralidad ${ }^{31}$ justifican, pues, analizar en profundidad su eventual inclusión en las más diversas áreas del conflicto jurisdiccional civil.

\subsection{El inevitable recurso a la buena fe y colaboración entre partes}

En estrecha relación con las nociones recién expuestas, conviene observar que los principios de buena fe y de colaboración entre las partes para alcanzar los más diversos objetivos resultan ser particularmente armónicos, tanto con la adopción de fórmulas o herramientas de solución de conflictos que incluyan ERTEP (discovery o disclosure), que impiden la asimetría de las posiciones que ocupan los interesados desde la perspectiva de los sustentos fácticos e incluso jurídicos de sus pretensiones puestas en conflicto que suelen conducir a un pleito "carried in the dark" con una severa afectación a las garantías del debido proceso ${ }^{32}$, por una parte, como con el recurso a un amplio rango de herramientas y mecanismos $\mathrm{SARC}^{33}$, a los que la aplicación

\footnotetext{
28 Niemeyer (1998), p. 519.

29 TWINING (1993), pp. 389-390.

30 Mullerat (2002), p. 58.

31 Por todos: Taruffo (2008), p. 8.

32 TARuffo (2008), p. 9.

33 Barona (2010), p. 462.
} 
de las ERTEP, como se dijo, muchas veces conducen ${ }^{34}$ permitiendo, además, asegurar la determinación justa, expedita y barata de la naturaleza y curso de cada acción, uno de los objetivos declarados de la introducción de estas reglas ${ }^{35}$.

De hecho, el requerimiento de buena fe de las partes resulta ser tan consustancial a estas etapas de la fase preliminar del juicio (casi desconocida, por su escasa relevancia, hasta hace poco tiempo, en el ámbito de los procesos civiles, como el chileno, propios de ordenamientos adscritos a la regla del juzgamiento jerárquico del civil law $\left.{ }^{36}\right)$, que la normativa norteamericana que estatuye la misma (las Federal Rules of Civil Procedure o FRCP) y, en su contexto, las instituciones del disclosure y del discovery, reiteradamente recurren a la buena fe con que los litigantes deben afrontar estos procedimientos ${ }^{37}$, recurso que en ordenamientos inspirados en mayor o menor medida en el modelo norteamericano, como el japonés, es replicado con particular énfasis, entregando su verificación a la conducta procesal que han de observar las partes ${ }^{38}$ y que, en definitiva, se reproduce en los diversos procesos de modernización de la justicia ${ }^{39}$.

Aun cuando es preciso tomar debida nota de las tendencias unificadoras del concepto, parece ser más o menos cierto que la exigencia de buena fe, tanto para el desarrollo exitoso de las ERTEP como para la adopción de las fórmulas SARC a las que las primeras dan lugar, se refiere a una buena fe objetiva, como criterio normativo de evaluación de la conducta del contratante ${ }^{40}$, o del interesado, en este caso $^{41}$, aun cuando este evento se presta especialmente para abonar la necesidad de adoptar una concepción unitaria de la buena fe, pues, como enseña la dogmática: "... no existe una buena fe subjetiva sin una conducta conforme a la buena fe, ni la corrección ni la rectitud que exige la

\footnotetext{
34 Mullerat (2002), p. 58.

35 HeNCH (1994), p. 185.

38 Subrin (2002), p. 303.

${ }^{39}$ Carretta (2013), p. 193.

40 Carvajal (2011), p. 54.

${ }^{41}$ BOETSCH (2011), p. 81.
}

${ }^{36}$ Hazard y Taruffo (2006), p. 141.

37 Así, por ejemplo, Rule 26 (4) (c), Rule 26 (f) (4), Rule 26 (g) (2) (A). El recurso a la buena fe de las partes se hace presente en forma particularmente relevante en aquellos casos en que la ley impone sanciones para la parte que incurre en una reticencia injustificada de colaborar con el proceso o en la entrega de información incompleta o falsa: Rule 37 (a) (2) (B), Rule 37 (a) (4) (A), Rule 37 (d), Rule 37 (g). 
buena fe es una formalidad externa, sin contenido alguno ${ }^{\prime \prime 42}$. Se busca, pues, que el mencionado principio de buena fe inspire, por lo tanto, una conducta de cooperación entre las partes ${ }^{43}$, noción que satisface los intereses de los interesados, tanto en la adopción de soluciones de compromiso, como en la litigación exenta de asimetrías.

Es así como se produce aquí un relevante punto de contacto que hermana las ERTEP con los SARC, pues no existe motivo alguno para relevar al interesado de observar una conducta inspirada en estos principios precisamente en el momento en que la colaboración entre partes es críticamente crucial: en la crisis de la vinculación civil o comercial. Resulta lícito concluir por lo tanto que, sin perjuicio de las múltiples y riquísimas conexiones que existen entre el discovery y los ADR, casi unidos en una verdadera relación de causalidad, como se verá a continuación, subyacen todavía profundos motivos sustantivos que estructuran y refuerzan esencialmente dicha unión, cifrados en los ya mencionados principios de buena fe y colaboración sin los cuales la vinculación jurídica entre los contratantes o interesados de cualquier relación jurídica convencional es sencillamente inimaginable, ya que ella no pretende modelar solo una consideración valórica de dichas conductas, sino que entregar un juicio verdaderamente jurídico de las mismas a partir de elementos de sostén, asimismo, jurídicos ${ }^{44}$.

No obstante lo que se lleva descrito, se hace necesario en este punto consignar las diversas concepciones que al instituto de la buena fe se le da en el medio continental (y por lo tanto, chileno) y los de herencia angloamericana, pues: "... la enunciación general de 'obrar de buena fe' les ha de servir de poco (a los ordenamientos angloamericanos) y les resulta amenazante, desde que evoca la idea de una moral contractual dirigida por el juez que limita la libertad de conciencia ${ }^{1 / 45}$ las que, sin embargo, no parecen distanciarse tan radicalmente cuando se trata de comunicar estas nociones al proceso civil o a la solución de conflictos civiles o comerciales, dentro o fuera del aparato estatal $^{46}$, permeando de esta manera las soluciones procesales que se estruc-

\footnotetext{
42 Boetsch (2011), p. 85.

43 BOETSCH (2011), p. 118.

44 Carvajal (2011), p. 66.

45 Segura (2011), p. 107.

46 Con todo, el concepto no parece tan lejano a lo menos en la materia propuesta como objeto de investigación, pues: "En la jurisprudencia angloamericana se ha entendido como actuaciones de este tipo (contrarias a nociones generales de honestidad o de interdicción al engaño o fraude), el actuar con opresión sobre la conciencia del contratante, con sorpresa injusta o pactando cláusulas totalmente desiguales que no será esperable que una persona razonable acepte en condiciones normales".
} 
turan en torno a dichas nociones elementales, dando forma a las instancias de discovery y disclosure enfocadas hacia el ya tantas veces señalado objetivo ${ }^{47}$.

En suma, buena fe y colaboración entre partes, sea cuál sea la lectura que se les dé, conforman un punto de contacto esencial entre las ERTEP y Ios SARC, al extremo que es posible sostener que, si existe un concepto que resulte transversal a ambos y que sirve, por demás, de vaso comunicante entre los dos, es precisamente este, en una vinculación efectivamente causal.

\subsection{Caracterizando el discovery, el disclosure y su inserción en el proceso civil norteamericano}

Llegados a este punto de las reflexiones que nos ocupan, se impone llevar a cabo un repaso más cercano del estado actual tanto del perfilamiento como de la aplicación de las instituciones de revelación temprana de evidencia en los ordenamientos en que se han desarrollado en mayor medida las mismas y, concretamente, en los Estados Unidos de Norteamérica.

En el caso del Reino Unido, las instancias de discovery y disclosure se encontraban tradicionalmente limitadas a los medios de prueba documental, ello por lo menos hasta la reciente reforma del proceso civil acometida en dicho ordenamiento ${ }^{48}$ que en esta materia incluso restringió aún más el proceso $^{49}$, de manera que resulta aconsejable hacer referencia al estatuto estadounidense, en la medida en que cuenta tras de sí con una larga evolución que ha permitido, tanto al foro como a la academia, apuntar sus fortalezas, sus debilidades, y ofrecer modelos que, de hecho, el propio ordenamiento británico ha seguido ${ }^{50}$, aun cuando radiquen su inspiración en fuentes propias, como ocurre claramente con el "Informe Wolf" que sirvió de base a la reforma de 1999, cuyo significado, en torno a este particular es, empero, sensiblemente análogo al norteamericano ${ }^{51}$.

Parece preciso recordar, de hecho, que en el modelo del common law el juez se encuentra autorizado a invocar precedentes de ordenamientos de

Segura (2011), p. 110 (el subrayado es nuestro). El punto de conexión con la materia en estudio y, especialmente, con los objetivos del discovery es evidente.

47 "Del propósito procesal sigue la forma, cuando está implicada en él conceptualmente. Allí donde puede demostrarse esa implicación conceptual, las formas procesales surgen de los propósitos subyacentes como una serie de muñecas rusas". DAMASKA (2000), p. 165.

${ }^{48}$ CPR, 1998, p. 31.

49 Andrews (2013), p. 76.

${ }^{50}$ VAN Rhee (2002), p. 32.

51 Andrews (2013), p. 77. 
idéntica inspiración, de manera que mucho de lo que se pueda predicar de instituciones, aun adjetivas, de un ordenamiento, resulta propio del otro ${ }^{52}$, proceso de integración en constante evolución gracias al fundamental aporte del estudio comparatístico ${ }^{53}$, incluso en el medio continental.

Las ERTEP (disclosure y discovery), en los ordenamientos norteamericano e inglés, se insertan en una fase preliminar del proceso ${ }^{54}$, esto es, terminada la primera etapa de discusión constituida por la demanda (complaints) y su contestación (answers), ambas escritas. Dado que los instrumentos básicos de la etapa de discusión delinean la cuestión debatida en términos muy genéricos, resulta insoslayable la necesidad de una fase preliminar, con posibilidades amplias de revelación y búsqueda de evidencia, que permitan avanzar hacia la precisión de la cuestión debatida, tanto desde un punto de vista jurídico como, muy especialmente, de los hechos que configuran los pleadings o posturas que van a sustentar las partes ${ }^{55}$.

De hecho, la configuración final de los pleadings de cada una de las partes viene a resultar producto de la actividad desarrollada en esta etapa de pre-trial en que las pretensiones se enfrentarán a las evidencias con que pretenden sustentarse y aquellas que el contradictor esgrimirá en su defensa, delimitando con ello el objeto de la controversia ${ }^{56}$.

El discovery de carácter amplio y omnicomprensivo, por lo mismo que se Ileva explicado, se encuentra estrechamente vinculado con el litigio bajo la fórmula del notice pleading ${ }^{57}$ que permite, en los ordenamientos angloamericanos que lo acogen, deducir demandas extremadamente sucintas, escuetas, cuyo objetivo principal no avanza más allá de la declarada finalidad de poner a la demandada en antecedentes de la acción que se anuncia entablar en su contra, huyendo del formalista code pleading imperante hasta la reforma de 1938 , no muy distinto de las antiquísimas acciones formularias ${ }^{58}$ y que resultaba manifiestamente reñido con un procedimiento de inspiración adversarial ${ }^{59}$.

52 Nota característica del common law que, sin embargo, la progresiva adopción de estatutos legislados ha ido limitando en forma importante.

${ }^{53}$ Chase (2005), p. 84.

${ }^{54}$ Hazard y TARuffo (2006), p. 123.

55 Gilsanz (2010), p. 96.

${ }^{56}$ Gilsanz (2010), p. 96.

57 HeNCH (1994), p. 185.

58 NieMEYER (1998), p. 518.

${ }^{59}$ De hecho, esta simplificación de las presentaciones iniciales ha derivado en Inglaterra al extremo de admitir la litigación mediante formularios predeterminados y disponibles para cualquier interesado, incluso por medios electrónicos. EINHAus (2008), p. 241. 
Es por ello que se ha afirmado que en los Estados Unidos, el notice pleading conforma, junto con el discovery, una dupla de vinculación indisoluble, que da lugar, a su vez, a uno de los principales pilares de la regulación de la litigación civil en dicho ordenamiento ${ }^{60}$. Es preciso señalar, con todo, que se ha reparado en que el notice pleading se ha visto severamente afectado por la introducción del disclosure obligatorio de 1993: dado que la parte se encuentra obligada a revelar espontáneamente (disclose) solo aquella información que se relacione directamente con las afirmaciones de la demanda inicial; las partes que cuentan con poca información inicial se encuentran en un pie de inferioridad frente a aquellas que manejan volúmenes importantes de la misma (típica asimetría, por ejemplo, de los casos de consumo o de las acciones de clase), pues estas podrán siempre alegar que cumplen con su obligación revelando volúmenes acotados de información, lo que a su vez obliga a aquellos demandantes a formular demandas mucho más extensas y detalladas, en contra del principio que sostiene la litigación sobre la base de nociones de notice pleadings, perjudicando así a las partes más débiles, por ejemplo, en cuestiones en que se reclaman perjuicios de grandes corporaciones o de derechos fundamentales ${ }^{61}$.

Las ERTEP recién singularizadas, insertadas en las etapas preliminares del proceso de juzgamiento estatal heterónomo y muy especialmente antes de verificarse el juicio propiamente dicho, permiten, como un efecto facilitado por su propia fisonomía, a una cualquiera de las partes, instar por un cierre expedito del proceso (y con ello del discovery), mediante una resolución del litigio in limine, solicitando al juez (a través de una motion) que la cuestión sea resuelta desde ya, debido a que las cuestiones de hecho que presenta la evidencia revelada no tendrán incidencia en la resolución de la controversia (también conocida como general demurrer), sosteniendo la inadmisibilidad de la demanda, que se resolverá en ese caso en sede estrictamente jurídica (ya que los hechos, se sostiene, son irrelevantes) o bien, lo que es más común, presentar una pretrial motion a fin de que la cuestión sea resuelta por el juez mediante un summary judgment o decisión sumaria, mecanismo este que supone que los hechos se encuentran ya propiamente establecidos, sin mayor cuestión, a partir de la evidencia que se reveló en la etapa preliminar ${ }^{62}$ y que, por lo tanto, no queda sino aplicar el derecho a ese sustrato fáctico

\footnotetext{
60 NiemeYer (1998), p. 520.

61 HeNCH (1994), p. 183.

62 VIAL (2006), p. 709.
} 
ya inamovible ${ }^{63}$, ello sin necesidad de llevar a cabo un juicio propiamente dicho ${ }^{64-65}$. Constituyen estas, por lo tanto, particulares formas alternativas de resolución del conflicto al interior del propio aparato estatal, pero apartadas del juzgamiento tradicional que es necesario evaluar para explicar su inclusión dentro del amplio catálogo de SARC que el estatuto estadounidense contempla.

Aun cuando es cierto que el Juez puede desestimar las peticiones dirigidas a resolver el conflicto en estas etapas tempranas del proceso, no lo es menos que ellas demuestran el especial valor que reviste la revelación de evidencia, pues estas instancias harán patentes, con un apreciable grado de certidumbre, las fortalezas y debilidades de las pretensiones de las partes, al tiempo que permitirán delimitar de mejor forma el conflicto, permitiendo con ello su resolución de manera expedita y sumaria, ofreciendo así una muy relevante solución alternativa al conflicto, distinta de su fallo mediante una sentencia dictada en forma de instancia, eliminando de paso expectativas irreales o exorbitantes de las partes, disonantes de la verdadera envergadura y contexto del diferendo en curso. Áreas de litigación tan importantes como el contencioso administrativo en los EE.UU. que involucra, entre otros, y muy especialmente, la responsabilidad por actuaciones perjudiciales de las FF.AA. se suelen resolver, en una proporción muy relevante, mediante summary pleadings, lo que demuestra su amplio espectro de aplicación ${ }^{66}$.

Estas sumarias formas heterónomas de resolución del conflicto presentan, además, y muy especialmente, la ventaja, a lo menos entre nosotros, de no verse afectadas por uno de los más graves cuestionamientos que suelen afectar a las fórmulas autocompositivas de resolución del conflicto: se involucra en ellas a la administración estatal de justicia y, por lo tanto, no se les puede

63 Hazard y Taruffo (2006), p. 137.

64 Gilsanz (2010), p. 96.

65 Mullerat (2002), p. 57. Este mecanismo de resolución del conflicto en sede sumaria tiene un interesante correlato en dos ADR bien definidos, a saber, el juicio sumario ante jurado (summary jury trial) y el minijuicio (minitrial). Ambos revisten la característica de ser, a la vez, un mecanismo autocompositivo, pero que ofrece a las partes el veredicto de un tercero imparcial designado como juez, en el primer caso, o como presidente de un Consejo, en el segundo, no vinculante, pero que la práctica ha demostrado poseer particular autoridad. El ofrecimiento de ambos ADR se inserta, precisamente, en la etapa de discovery.

66 Suele citarse aquí como ejemplo paradigmático el caso "Agente Naranja", en que miles de exuniformados que sirvieron en Vietnam en los 60 y 70 sufrieron la contaminación por el agente desfoliador del mismo nombre. Ninguno de estos casos ha llegado a ser resuelto en sede judicial tradicional, generándose una rica trama de SARC a su alrededor, bien que se impone tomar nota que en algunos casos ello se ha prestado a abusos radicados en situaciones de mala praxis deontológica. Así en RESNIK (1986), pp. 524 y 549. 
achacar que ellas importen privar a los interesados de su garantía fundamental de acceder a aquella al forzarlos, de alguna manera, a recurrir a soluciones de compromiso o mediadas, reparo que también se presenta, por cierto, en medios en que la aplicación de los SARC se encuentra tan extendida, como ocurre paradigmáticamente con el common law en los Estados Unidos de Norteamérica ${ }^{67}$.

Las instancias de discovery y disclosure tienen por objetivo, por tanto, no solo revelar la prueba con que cuenta la propia parte, impidiendo con ello unfair surprises ${ }^{68}$ o "juicios por emboscadas" ${ }^{69}$ que pongan en riesgo la simetría que deben observar aquellas, como también, y este es uno de sus principales roles, el permitir la recopilación de evidencia en abono de las propias pretensiones ${ }^{70}$, todo ello estructurado sobre la base de las así llamadas pretrial conferences, instancias de reunión prejudicial en que las partes, primero por sí mismas y luego, de ser ese el caso, con asistencia del juez a cargo del caso, harán manifestación de sus medios de prueba, recabarán la manifestación de la parte contraria y plantearán un programa de descubrimiento que el Juez debe aprobar, previo al juicio. Acá radica, de hecho, la diferencia distintiva entre los conceptos de discovery y disclosure: el primero, en términos generales, ha sido definido como un "procedimiento mediante el que las partes obtienen formalmente información relevante de la controversia (...) regulado en las reglas 26 a 37 de las Federal Rules (y que) es el elemento más característico y diferenciador del proceso civil en Estados Unidos ${ }^{\prime \prime 71}$, pero en estricto rigor, el discovery conforma, junto el disclosure, el conjunto de las técnicas de revelación temprana de evidencia que se emplazan en la etapa de pretrial y que tienen como eje central la pretrial conference, instancia prejudicial que requiere de las partes una particular motivación colaborativa, toda vez que ha sido concebida para ser desarrollada, en principio, sobre la base de reuniones preliminares en ausencia del Juez y con la asistencia de los abogados de las partes, las partes mismas y, eventualmente, terceros interesados en la cuestión a debatir ${ }^{72}$.

El juez, por su parte, a diferencia de otros ordenamientos que se han inspirado en el estadounidense, como el japonés, mantiene un rol más bien

\footnotetext{
67 TWINING (1993), p. 381.

${ }^{68}$ TARUfFo (2008), p. 10.

${ }^{69}$ Andrews (2013), p. 75.

70 SUBRIN (2002), p. 301.

71 Gillsanz (2010), p. 96.

72 Gilsanz (2010), p. 101.
} 
pasivo $^{73}$, por una convicción profundamente arraigada en la propia cultura procesal del common law en general y, muy particularmente, estadouniden$\mathrm{se}^{74}$, fenómeno este que responde, por demás, en términos más generales, a la desconfianza que impera en dicho medio hacia la concentración del poder en una sola autoridad, aunque esta sea judicial y que parece encontrarse en la base del andamiaje procesal civil en esos ordenamientos, al menos en el contexto de las instituciones que nos ocupan ${ }^{75}$ y que responde a un rasgo característico de los así llamados modelos "paritarios" de administración de justicia que les entrega a los abogados litigantes porciones muy relevantes de injerencia directa en la estructuración del proceso, como ocurre típicamente con estas instancias ${ }^{76}$.

Las nociones anteriormente descritas permiten, adicionalmente, trazar la línea distintiva entre el disclosure y el discovery en términos estrictos. Mientras las primeras revelaciones deben nacer de la parte motu proprio, antes de esperar el requerimiento de la contraria y tan pronto como se arriba a la etapa de la reunión entre los abogados, de acuerdo a la Rule 26 (a) (1), la segunda nace precisamente de un emplazamiento de la contraria formulado a partir de la reunión preliminar de los abogados regulada por la Rule 26 (f) y del plan de discovery que las partes se han propuesto en dicha oportunidad, el que se presentará al Juez en la pretrial conference quien, de aprobarlo, fijará un scheduling order que programará los tiempos que regularán lo restante de la etapa preliminar ${ }^{77}$.

73 SUBRIN (2002), p. 301.

74 SUBRIN (2002), p. 309.

${ }^{75}$ Subrin (2002), p. 309.

76 DAMASKa (2000), p. 112.

77 El establecimiento de las disclosures en una etapa inicial, voluntaria y espontánea de las pretrial conferences fue, de hecho, una de las modificaciones más importantes que introdujo la reforma de 1993 a las FRCP. Dicha reforma autorizó, con todo, en la propia Rule 26 (a) (1) una exclusión de la fase de disclosure bien por disposición del tribunal, bien por pertenecer a algunas de las categorías excluidas normadas por la propia FRCP en la Rule 26 (a) (1) (E), conocidas genéricamente como privileges, categoría que cubre, además, requerimientos de discovery impugnados por las partes por improcedentes, como ocurre con la información proveniente de la carpeta de trabajo del abogado, o bien de las reuniones que este haya sostenido con su cliente. Estas exclusiones (que hasta una reforma de 2000 incluían, además, la posibilidad de exclusión por efecto de reglas de las Cortes locales) conforman los así llamados casos de opt-out del disclosure. Con todo, se ha demostrado que el disclosure es cada vez más prevalente, aun en los casos en que podría comportarse una situación de opt-out, y que a la larga, se han logrado los objetivos que motivaron su establecimiento, esencialmente, la reducción de los costos del litigio, una disminución de la densidad del discovery, una mejora en los tiempos de tramitación, una reducción en 


\subsection{Externalidades positivas de las ERTEP. Sus peculiaridades y extensión}

Más allá de los reparos que se puedan formular en relación con la calidad de las soluciones que ofrece para cada caso en particular, queda en evidencia que la etapa preliminar del juicio recién expuesta ofrece, en el ordenamiento que sirve a nuestro análisis, múltiples oportunidades para presentar a los interesados importantes incentivos para alcanzar soluciones alternativas, mediadas, arbitrales, transaccionales, o incluso de resolución judicial sumaria y expedita ${ }^{78}$. Esta última consideración que supone, desde luego, adoptar un partido claramente favorable en torno a fomentar el uso intensivo y extendido de los SARC del más amplio espectro y naturaleza ${ }^{79}$ (y que responde con toda precisión al modelo del multidoor court room) aconseja, además, la adopción de este género de herramientas y su inserción, precisamente, en etapas tempranas del conflicto judicial, fortaleciendo de esta manera una etapa preliminar que actualmente, entre nosotros, carece de relevancia y que, por cierto, no permite distinguir entre etapas preparatorias del juicio y de juicio propiamente dichos.

No resultará sorprendente, tampoco, que sea en estas etapas donde se verifique el mayor número de salidas hacia soluciones alternativas del conflicto $^{80}$ : en ellas se requiere de un activo rol de colaboración tanto de parte de los interesados como del propio juez, el que no resulta del todo diverso

la litigiosidad en torno al discovery, un incremento en la percepción de equidad en la recepción de prueba y, muy importante, un aumento de los casos que optan por soluciones MASC. De hecho, la experiencia indica que un disclosure activo suele enlazarse con un discovery, asimismo, dinámico y productivo. Willging et al. (1998), p. 535, ello aun en contra de la opinión inicial de doctrina o jurisprudencia, pues la introducción del disclosure obligatorio al contexto más general de las estrategias de discovery, en la reforma de 1993, fue objeto de severos cuestionamientos, toda vez que se afirmó que produciría una asimetría en el acceso a la justicia dependiendo de la información con que contaren las partes, reparos que eran ampliamente compartidos, incluso al interior de la Corte Suprema. HeNCH (1994), p. 181.

${ }^{78}$ Hazard y Taruffo (2006), p. 137.

79 Iniciativa hoy presente entre nosotros incluso a partir del interior de la sede judicial, según se puede leer en el instrumento de planificación estratégica del Poder Judicial 2015-2020. PODER JUDICIAL (2015).

${ }^{80}$ Esta observación se formula, claro está, en lo que toca a aquellos casos en que efectivamente se verifica un proceso de discovery, pues es un hecho que en eal contexto de litigios de escasa cuantía o de baja complejidad, los abogados sencillamente no desarrollen este tipo de actividad, dirigiéndose directamente al juzgamiento, la mayor parte de las veces, simplificado. En el ámbito de los tribunales federales, la estadística disponible de la década de los 90 del siglo XX consigna que en un 38\% de los casos no se había desarrollado discovery, mientras que en los tribunales estatales, ese porcentaje alcanzó el 42\%. Así en SubRIN (2002), p. 308. 
ni distante del que han de observar al desarrollar diversas soluciones autocompositivas del conflicto, como lo son la mediación y la conciliación ${ }^{81}$, esta última de antigua raigambre en nuestra cultura jurídica (aun cuando se objete su profundidad y eficacia) y que puede representar, precisamente, un punto de anclaje de la inserción de estas fórmulas entre nosotros, tal y como ocurre, hoy en día, con la rica experiencia que ofrece el proceso de mediación en materia de responsabilidad sanitaria, introducida por la ley $N^{\circ} 19.966$, cuyos estudios empíricos demuestran un interesantísimo descenso en las tasas de judicialización en dichos asuntos que, aun no alcanzando un acuerdo o solución mediada, se mantienen al margen del aparato judicial ${ }^{82}$.

La diversa naturaleza de los disclosures y discoveries, radicada en la espontaneidad (o automaticidad) de los primeros frente al forzamiento de los segundos, marca además los mecanismos a través de los cuales se concretan unos y otros, enmarcados ambos, eso sí, en un amplio contexto de admisibilidad que solo tiene por excepción aquellos privileges o exclusiones, expresamente normados por la ley o declarados por la instancia judicial para los casos en que se demuestra que la revelación de alguna evidencia resulta ilegal, inconveniente o desaconsejable ${ }^{83}$. De hecho, una parte importante del litigio en esta etapa del proceso radica, precisamente, en llevar a los casos concretos el alcance que tendrán estos privileges y que le permitirán al litigante excusarse de revelar evidencia, sea espontánea o forzadamente, tanto es así que una de las principales líneas de reformas propuestas a las reglas del discovery dice precisa relación con la estrechez de las reglas que permiten amparar, por ejemplo, el secreto profesional de la revelación de evidencia ${ }^{84}$, particularmente caro en un medio en que la privacidad en todas sus formas es vigorosamente protegida.

Así, y esta es una de las maneras en que se concreta el procedimiento, el disclosure del litigante estadounidense se expresará mediante la manifestación, espontánea como se dijo, de la identidad de las personas que cuentan con información en torno al caso sub lite, copias o designaciones de documentos o especies en poder de la parte que la presenta, determinación de los daños o mecanismos empleados para calcularlos y muy especialmente la información relativa a los peritos cuya intervención se requerirá en el curso

81 Barona (2010), p. 462.

82 Unidad de Mediación Consejo de Defensa del Estado (2011).

83 Gilsanz (2010), p. 99.

84 NiemeYer (1998), p. 523. 
del juicio ${ }^{85}$, manifestación esta última que no se satisface únicamente con la individualización del experto ni con la entrega de un informe escrito, sino que requiere importantes antecedentes adicionales, como la exhibición de las evidencias materiales que basan el informe, una lista de las publicaciones de las que el perito sea autor en los pasados diez años, las sumas que se le pagarán por su desempeño y un listado de todos los casos en que haya actuado el perito en los últimos cuatro años ${ }^{86}$.

En el Reino Unido el proceso es sensiblemente más sencillo, pues bastará con que las partes pongan a disposición de la contraria copias escritas de la declaración que formulará el testigo y del informe del perito para que se dé por cumplida su obligación en este punto ${ }^{87}$.

Tan acabado es el proceso de revelación y descubrimiento de los peritos en los Estados Unidos, que se ha demostrado que este resulta ser uno de los factores que más incrementan los costos del proceso de discovery en general ${ }^{88}$, lo que ha redundado en que esta sea una herramienta relativamente poco utilizada en el contexto general del disclosure ${ }^{89}$ en un medio (el norteamericano) en el que, por regla general, un porcentaje importante de la litigación rutinaria (por motivos de baja cuantía o de escasa complejidad de lo debatido) derechamente no hace uso alguno del discovery, o bien hace un uso completamente acotado a las necesidades del caso y basado en reuniones puntuales entre los abogados ${ }^{90}$, lo que ha venido a refutar que la sola consideración del costo económico, relevante como es, sea una cuestión excluyentemente preponderante a tener en cuenta al establecer con mayor o menor amplitud este tipo de mecanismos ${ }^{91}$, superando un punto crítico a la forma como ha venido evolucionando la institución en los Estados Unidos de Norteamérica ${ }^{92}$.

La reticencia a dar cumplimiento a la obligación de disclosure o la expresión mendaz o incompleta de sus elementos, una vez emplazada la parte por el Juez, es sancionada con importantes cargos económicos y con la preclusión del derecho de la parte a valerse en cualquiera de las etapas del proceso de la

\footnotetext{
85 Gilsanz (2010), p. 97.

86 FRCP, rule 26 (a) (2) (B).

${ }^{87}$ CRP (1998), pp. 34 y 35.

${ }^{88}$ Willging et al. (1998), p. 566.

${ }^{89}$ Willging et al. (1998), p. 544.

90 Niemeyer (1998), p. 522.

91 Niemeyer (1998), p. 522.

92 Oberer (1987), p. 3.
} 
evidencia afectada por la reticencia o desacato de la parte ${ }^{93}$, quebrantamiento del principio de buena fe y colaboración entre litigantes que es particularmente grave, como se dijo, a los ojos del legislador norteamericano de las FRCP. Aun cuando se ha comprobado que el endurecimiento de las sanciones al litigante de mala fe no ha importado un efecto notorio en la reducción del uso abusivo del discovery ${ }^{94}$, su sanción sí proporciona al litigante de buena fe un alivio económico de importancia, al imponer en su contradictor el cargo de costear la erogación que representa el proceso.

Las herramientas al interior del discovery estadounidense, a su turno, se estructuran en torno a cuatro mecanismos concretos, a saber, las depositions, o declaraciones de testigos desarrolladas en presencia de los abogados de las partes y de un oficial del tribunal a cargo de su juramento, del que se levanta acta literal o grabada por medios electrónicos; el examen de documentos, evidencias materiales o examen de lugares determinados; el examen físico o mental de un sujeto para determinar sus condiciones de salud (área donde se verifica de manera muy relevante la litigación en torno a los privileges o excusas legalmente respaldadas de revelar) y las solicitudes de admisión, en cuya virtud una parte solicita a la otra que reconozca ciertas circunstancias o hechos que la parte que formula la moción propone por escrito ${ }^{95}$. Las circunstancias así reconocidas se dan por plenamente probadas, sin que sea admitida la revocación de la declaración a menos que una orden judicial así lo determine a petición de la parte afectada ${ }^{96}$, ello a pesar de que la propia ley autoriza a la parte emplazada para declarar, a sustituir su comparecencia por el examen de registros y archivos en que la parte solicitante pueda encontrar la materia en concreto que motiva la solicitud de declaración ${ }^{97}$.

Las diligencias de discovery, como se dijo, se incluyen en la programación que las partes ofrecen al juez en el marco de la pretrial conference, de suerte tal que serán avaladas por una orden emanada del tribunal que, si bien cuenta con facultades legales para adoptar un rol activo en la misma, hoy en día específicamente reforzado por la reforma de 2015, no suele intervenir más que a petición de parte formulada por medio de motions que serán atendidas en dicha oportunidad ${ }^{98}$. Con todo, el hecho de verse respaldado por una

\footnotetext{
93 FRCP, Rule 37 (c) (1).

$94 \mathrm{HeNCH}$ (1994), p. 193.

95 Hazard y Taruffo (2006), p. 129.

96 FRCP, Rule 36 (b).

97 FRCP, Rule 33 (d).

98 Gilsanz (2010), p. 101.
} 
resolución judicial permite que la motion sea amparada bajo la sanción de ser declarado en desacato (in contempt of the court) y aplicarse bajo apercibimiento de ser objeto de las sanciones económicas y procesales contenidas en la Rule 37 de las FRCP.

Es a este último punto al que se dirigen, de manera muy especial, las reformas introducidas al procedimiento de discovery, a saber, al rol que le corresponde al juez en el mismo. Existe cierto consenso en dogmática y jurisprudencia norteamericanas de que una de las maneras más propias de alcanzar un adecuado equilibrio entre los costos y el tiempo que demanda una instancia de este tipo, y el derecho del litigante a conocer la prueba de su contrincante para poder ensamblar de manera correcta su teoría del caso, es la proporcionalización de la misma etapa, esto es, fijando al proceso un marco armónico con la relevancia, jurídica, económica o social, del conflicto $^{99}$, delimitación esta en que le cabe un papel preponderante al juez. No cabe duda, por otra parte, que la tendencia actual, y así lo demuestra la ya referida reforma de 2015, es a proporcionarle al juez civil norteamericano (al menos al federal) un rol más activo, precisamente en esta área, es decir, Ilamándolo a velar por que se cumpla con una proporcionalidad racional del discovery que, mediante mecanismos de control del mismo, impida un uso abusivo de la institución, como el que se ha dado con frecuencia en la práctica forense en ese medio y que ha terminado, en buena medida, por desprestigiar la misma ${ }^{100-101}$, asumiendo un rol gestionador del proceso (managerial judge).

Existe consenso, además, en que la intervención judicial temprana resulta valiosa, además, para racionalizar y reducir los costos del proceso de discovery tanto en términos económicos como de tiempos involucrados, a cuyos efectos se ponen en poder del juez herramientas tales como la fijación de límites temporales para llevar a cabo el proceso en cuestión, explícita o cuando menos implícitamente, determinando fechas inamovibles para llevar a cabo la audiencia de juicio lo que implica, como es lógico, la necesaria conclusión de aquel ${ }^{102-103}$, punto este (el de poner en relevancia el protagonismo temprano del juez en la determinación del objeto de la controversia) en que se verifica

\footnotetext{
99 Subrin (2002), p. 313.

100 SUBRIN (2002), p. 309.

101 HeNCH (1994), p. 181.

102 Niemeyer (1998), p. 523.

103 Así adoptado en la reciente reforma de abril de 2015 a las FRCP: Hunton y WiLliams (2015).
} 
un importante punto de contacto entre los ordenamientos del common y del civil law ${ }^{104}$, especialmente en aquellos de los últimos en que la adopción de diversas fórmulas de ERTEP se ha modulado, aun estatutariamente, sobre la base de los fines que persigue el proceso ${ }^{105}$.

En definitiva, y esto parece particularmente interesante para los procesos de modernización de la justicia que resuelvan incorporar algún género de discovery, se ha propuesto, en esta línea de razonamiento, reactiva a los efectos negativos que representa un discovery abusivo, instituir lo que se ha dado en Ilamar el discovery en tres niveles: el primer nivel dice relación con un disclosure básico obligatorio, que todo litigante debe observar en esta etapa del procedimiento y que no necesariamente debe contemplar declaraciones de testigos o la exhibición de medios de prueba cuya reproducción resulte particularmente onerosa, no muy diversa de aquella que se introdujo en el Reino Unido con las reglas de la Parte 31 de las CPR de 1998, especialmente acotada a la documentación relevante y atingente, que impida las así llamadas "expediciones de pesca"106.

Un segundo nivel requerirá ya del desarrollo activo de sesiones conjuntas de los abogados, que permitan definir prueba más concreta cuya revelación se requiera en este punto. Solo si los intereses del litigante no se ven satisfechos con esta etapa, se llega, por último, a la tercera, en que la intervención del juez es más activa, ya que debe aprobar el plan de discovery que las partes le presentarán, aplicando los apercibimientos y sanciones que sean de rigor ${ }^{107}$. La adopción de estructuras diferenciadas de este tipo parece haber resultado particularmente atractiva no solo en los Estados Unidos y en Reino Unido ${ }^{108}$, sino que en ordenamientos de inspiración tan diversa como Alemania ${ }^{109}$, Japón ${ }^{110}$,

\footnotetext{
104 Leipold (2008), p. 86.

105 DAMASKa (2000), p. 99.

106 ANDREWS (2011), p. 77.

107 Niemeyer (1998), p. 524

108 Subrin (2002), p. 305.
}

109 Código de Procedimiento Civil (ZPO) para. 142 ff., 422 ff. La ampliación del deber de revelación, legislado en Alemania en 2002, no ha dejado de causar cuestionamientos, precisamente debidos a su cercanía al discovery estadounidense. Así en WALTER (2006), pp. 77-78.

110 Código de Procedimiento Civil de 1996, arts. 132.2-132.3, reformados en 2003. Se instituyó en esta reforma la posibilidad de desarrollar estas instancias antes que la demanda fuese presentada. Así en Honma (2008), p. 260. 
Holanda ${ }^{111}$ o Canadá112, todos ellos, como es lógico, con diversos niveles de injerencia judicial que pueden insertar, a su vez, en los distintos niveles ya descritos del discovery.

Con todo, es preciso consignar acá una observación de profunda relevancia: así como existe, en los Estados Unidos, consenso en la utilidad y necesidad de las medidas ya mencionadas, tendientes a acotar el proceso de discovery a márgenes racionalmente proporcionales, con igual energía se ha afirmado, al menos en ese medio, que cada vez que en una litigación se ven involucradas garantías fundamentales de los interesados, debe imponerse el uso de un discovery amplio, proporcional a la gravedad de los derechos comprome$\operatorname{tidos}^{113}$ y así lo ha dictaminado la Corte Suprema de dicha nación ${ }^{114}$. No es coincidencia, por lo tanto, que la experiencia jurisprudencial norteamericana así lo demuestre, pues los tres leading cases en que la Corte Suprema de ese país conceptualizó el notice pleading compensado con un proceso amplio de discovery decían relación con litigación sobre derechos fundamentales (Conley v. Gibson de 1957, sobre discriminación laboral racial; Leatherman v. Tarrant County Narcotics Intelligence and Coordination Unit de 1993, sobre excesos policiales en sus facultades de registro, y Swierkiewicz v. Sorema, sobre discriminación laboral en razón de edad, de 2002) ${ }^{115}$.

Es así como el precedente jurisprudencial ha avalado la proporcionalidad del discovery que el propio legislador estadounidense vino más tarde a normar ${ }^{116}$, modulando la intervención del juez en una evolución que no se aparta del derecho continental, por demás ${ }^{117}$.

111 Código de Procedimiento Civil ( $W v B R v)$ arts. 87-88, reformado en 2002. Esta reforma asocia una etapa de discusión reducida a dos presentaciones esenciales con una ERTEP funcional a la determinación del objeto del litigio y a la exploración de alternativas de MASC, así en RUTGerS y RUtGers (2008), p. 138.

112 Rules of Civil Procedure, RRO 1990, rules 29.1 y siguientes. La extensión de la normativa relacionada a esta institución se ha ido extendiendo en paralelo a la norteamericana, así en SuBRIN (2002), p. 306.

113 SUBRIN (2002), p. 311.

114 CHASe (2005), p. 31.

115 SUBRIN (2002), p. 311.

116 Dispone la nueva regla 26 (b) (2) (1): “... (discovery) proporcional a las necesidades del caso, considerando la importancia de las materias en juego en la acción, la cuantía de la controversia, el acceso relativo de las partes a información relevante, los recursos de las partes, la importancia del discovery para resolver la cuestión y ponderando si el costo o carga del discovery propuesto sobrepasa el beneficio que se estima producirá el mismo".

117 Montero (2014), p. 29. 


\subsection{Las ERTEP en camino hacia los SARC}

A partir de la somera descripción que antecede, no resultará sorprendente ya que los efectos de la fase preliminar que se pretenden poner de relieve se verifiquen no solo al interior del proceso, en lo que dice estricta relación con la prueba (que, como se dijo, por cierto la tiene, y mucha) sino que también, y muy especialmente, fuera de él, pues tal y como se indicó precedentemente, una vez conocida la prueba del contradictor y determinada cuál será la prueba con que razonablemente la parte podrá contar durante el juicio, se coloca a las partes en una situación en que se les permite el acceso a una imagen clara de las fortalezas y debilidades del propio caso y de aquel de quien se presenta como adversario y con ello en vista, proceder a regular la envergadura de la institución sobre la base de las garantías procesales del propio litigante, estrechamente vinculadas a sus derechos en liza ${ }^{118}$.

El conocer con claridad y precisión la posición que, como litigante, enfrentará la parte al ventilar sus pretensiones en sede judicial, sumado a la ya mencionada actitud de colaboración activa que deberán observar en aras del éxito de la etapa de revelación, coordinada con idéntica predisposición del juez a coadyuvar con los interesados en el proceso, ora para finiquitar una etapa de revelación exitosa, ora para incentivar una solución pactada de la controversia, aun sin indicar una en concreto, resultará ser, por lo mismo, una poderosísima motivación para optar por la amplia gama de salidas SARC que establece el sistema norteamericano ${ }^{119}$ e incluso por alternativas, si bien judiciales, permiten una solución temprana, inmediata (y económica) de la controversia ${ }^{120}$, idealmente modelada a la medida del conflicto presentado, conformando en definitiva lo que se ha dado en Ilamar el tribunal con varias puertas de salida (multidoor court houses) "... donde las disputas individuales pudieran encontrar procedimientos apropiados tales como la mediación, el arbitraje, el fact finding, o paneles de examen de responsabilidad profesional' 121 .

Resultará lógico concluir, por lo tanto, que la adopción de fórmulas ERTEP resulta consonante e incluso casi ineludible para cualquier modelo de justicia adversarial ${ }^{122}$, pues al tiempo de representar un aporte esencial a fin de que los interesados opten por radicar su conflicto en alguno de los SARC que

\footnotetext{
118 Niemeyer (1998), p. 519.

119 Hazard y Taruffo (2006), p. 139.

120 Hazard Y TarufFo (2006), p. 137.

121 Mullerat (2002), p. 51.

122 TARuffo (2008), p. 8.
} 
ofrece el sistema ${ }^{123}$ (y que, de hecho, en los ordenamientos del common law norteamericano se encuentran ya institucionalizados, incluso como requisito de procesabilidad civil ${ }^{124}$, lo que ha redundado en que en aquellos solo una pequeña porción de los conflictos lleguen a judicializarse y de estos, una módica proporción concluya con una sentencia adjudicativa en forma ${ }^{125}$ ) importa eliminar las tan temidas asimetrías en la litigación civil.

Si se añade a lo anterior que la investigación empírica con que se cuenta ${ }^{126}$ logró desvirtuar la creencia, extendida hasta hace un tiempo en los ordenamientos del common law estadounidense e inglés, de que una etapa preliminar más o menos acotada de disclosures y discoveries incrementaría de manera radical los costos de litigar ${ }^{127}$ (una de las objeciones principales a la ampliación de estas instancias, pues por la fuerza de los costos se ponía al litigante débil, de todas formas, en una posición asimétrica de desventaja), se podrá concluir que su incorporación redunda en beneficios y ventajas que superan, largamente, los reparos que se puedan formular (y que de hecho, los hay $)^{128}$ y las dificultades que su inserción pueda representar, según pasamos a explicar en el apartado siguiente.

\section{El desafío latente que representa la inserción del discovery \& disclosure en los ordenamientos del civil law}

\subsection{Los puntos de conflicto que presenta la extrapolación de las ERTEP en los sistemas del common law}

En los apartados precedentes hemos bosquejado los lineamientos básicos de las instituciones del discovery y del disclosure, la manera en que ellas se insertan en los ordenamientos adjetivos comparados, particularmente del common law estadounidense y, muy especialmente, los beneficios que de ellas se derivan, en términos tales que nos hemos permitido calificarlas como de ambivalentes, pues sus efectos favorables se pueden detectar tanto al interior del proceso $(\mathrm{o}$, si se prefiere, al servicio de la forma heterónoma más clásica para la resolución del conflicto, como lo es el juicio estatal) ${ }^{129}$ como fuera de

\footnotetext{
123 Gilsanz (2010), p. 100.

124 Mullerat (2002), p. 61.

125 TWINING (1993), p. 382.

126 WiLlging et al. (1998), p. 531.

127 Oberer (1987), p. 3.

128 TARUFFo (2008), p. 16.

129 Barona (2010), p. 464.
} 
él, en la forma de presentar poderosos incentivos para que las partes opten por los diversos mecanismos autocompositivos de solución de controversias ${ }^{130}$ en la medida en que estos se tengan por benéficos.

Esta última calificación está sujeta, empero, claro está, a la consideración de dichos medios (como ocurre oficialmente entre nosotros) como una herramienta cardinal e imprescindible para la modernización de la justicia, lo que implica enfrentar los frecuentes reparos de los que suelen ser objeto, familiares aun en los ordenamientos comparados objeto de este estudio ${ }^{131-132}$, al extremo de existir importantes autores que han calificado los resultados obtenidos en dichos programas como "... doblar el brazo (del interesado) bajo la presión judicial"m33.

Con todo, no resultará erróneo sostener que la calidad del resultado de un proceso de negociación en el contexto de cualquier SARC resulta sensiblemente mermada por la asimetría de información entre los intervinientes del mismo, lo que lleva a sugerir, por lo tanto, que la inserción del discovery ha de ser previa a la oferta de este tipo de salidas alternativas, evitando así dejar a las partes en un manifiesto pie de desigualdad, lo que de hecho ha dado lugar a no pocos reparos al proceso ${ }^{134}$, ello aun cuando se ha descrito, en paralelo, que un discovery demasiado lato es en realidad contraproducente para los intentos de mediación ${ }^{135}$, de manera que representará una herramienta que es necesario utilizar conservadoramente, objetivo al que apunta, por cierto, la proporcionalización de aquel de que se trató anteriormente.

Con todo, ello no resultará suficiente aún para avalar la introducción, sin más, de estas instituciones en ordenamientos que clásicamente han seguido, como el nuestro, el derrotero del derecho continental o del civil law, en que el interesado en el conflicto jurídicamente relevante aún cifra en la respuesta estatal parte importante, si no todas sus muy justificadas expectativas de

\footnotetext{
130 SUBRIN (2002), p. 301.

132 ANDREws (2012), p. 275.

133 Glenn (2007), pp. 204-205.

134 Giannini (2014), p. 159.

135 SUBRIN (2002), p. 315.
}

131 Twining (1993), p. 381. De hecho, este autor refiere que Jeremy Bentham, quizás el jurista más influyente en la doctrina y jurisprudencia anglosajonas de los últimos 200 años, tenía una postura abiertamente recelosa hacia los ADR, limitando su utilidad a los lindes que le presentaba la ley sustantiva y afirmando, incluso, que las soluciones de compromiso que presentan se justifican solo cuando constituyen un mal menor. Presenta una cuestión de profundo interés dilucidar cómo los Estados Unidos dieron la amplia cabida que hoy tienen los ADR en un contexto imperado por las ideas de Bentham, contrarias, como se dijo, a este tipo de resolución del conflicto jurídico. 
justicia, propias por demás de la demanda por paz social emanadas de un Estado Constitucional de Derecho ${ }^{136}$, especialmente de organización judicial "jerárquica" que funciona bajo un auténtico espíritu de "exclusividad oficial'137, ello a pesar de que, como ya se examinó antes, un número importante de ordenamientos, de las más diversas tradiciones jurídicas, ha dado holgada cabida a este género de instituciones.

Entendiendo, pues, que la instauración de las ERTEP reporta un número de externalidades positivas que no resulta aconsejable dejar de evaluar en un proceso profundo de reformas a la administración de justicia, se hace necesario examinar cuáles son los principales obstáculos que representaría la instauración de este género de instancias en nuestras reformas locales, modeladas en etapas tempranas del proceso, lo que las diferenciaría, en buena manera, de las audiencias preparatorias hoy presentes en los juicios penales, de familia o laborales, que insertan bien adentrado ya el juzgamiento estatal heterónomo.

A juicio del autor, es posible reunir dichas cortapisas en dos apartados susceptibles de ser analizados por separado. En un primer lugar, resulta preciso analizar qué particularidades del discovery y del disclosure presentan elementos disonantes con un proceso civil adversarial concebido para un ordenamiento jurídico de corte continental o, si se quiere, en qué medida resultan contrarios a la naturaleza de la cultura litigiosa imperante entre nosotros $^{138}$, por una parte (y cómo se pueden superar, desde luego).

Seguidamente, en un segundo lugar, pero no por ello menos relevante, se ha de considerar de qué forma la inserción vigorosa y amplia de este género de instancias, quizás casi obligada por la abierta motivación por parte del aparato público hacia la adopción de un rol central los SARC en nuestro ordenamiento, representa una entidad ajena a la cultura jurídica específicamente nacional de inspiración continental, que claramente privilegia la aspiración de contar con una instancia de resolución del conflicto exclusivamente o mayoritariamente radicada en el órgano estatal, propia de la demanda por una respuesta pública, heterónoma y supra partes al diferendo de relevancia jurídica, característica común, por demás, a los ordenamientos continentales ${ }^{139}$.

Dicho en otros términos, se trata de dilucidar si la introducción de las ERTEP que, como empíricamente se ha demostrado, representan un poderoso

\footnotetext{
136 Barona (2011), p. 186.

137 DAMASKA (2000), p. 96.

138 Barona (2011), p. 193.

139 VAN Rhee (2005), p. 15.
} 
aliciente a las partes para abandonar el aparato público en pos de la búsqueda de soluciones autocompositivas del conflicto o inclusive heterónomas pero atípicas, entraña elementos ajenos a nuestra cultura jurídica que terminen por hacer inútil o incluso contraproducente su incorporación al ordenamiento adjetivo civil ${ }^{140}$, pues: "... cualquier propuesta para importar procedimientos judiciales procedentes de otra sociedad, debería requerir un contraste cultural... ${ }^{\prime \prime 41}$, consideración esta no siempre suficientemente ponderada por nuestros reformistas, quienes frecuentemente olvidan que: "La calidad de la justicia civil es una función de dos factores: (1) del diseño del procedimiento civil y (2) la medida en que dichas reglas sean aplicadas por los tribunales y respetadas por las partes. Sin importar cuán sensatos y bien diseñados puedan ser los procedimientos de un código, no llegarán a producir resultados satisfactorios si los litigantes no adhieren a sus reglas ${ }^{142}$ ", toda vez que: "... lo equivocado es centrarse en el atractivo de la forma procesal sin preguntarse si tal forma es compatible con un aparato judicial particular. La pregunta no es sólo qué tipo de procedimiento queremos, sino también qué tipo de organización del Estado poseemos ${ }^{\prime 143}$.

\subsection{La inserción de las ERTEP en el proceso chileno reformado}

El primero de los puntos parece ser más fácil de despejar, pues un sistema adversarial en forma, que entrega a la oralidad etapas relevantes del desarroIlo del juzgamiento, no solo permite, sino que incluso demanda, contemplar alguna suerte de ERTEP, por completo concordante y armónica, por demás, con las nociones de igualdad de armas, buena fe y colaboración entre los litigantes ${ }^{144}$ que imperan en este género de diseños procesales ${ }^{145}$, aun cuando su inspiración radique en tradiciones continentales o del civil law, de elevados niveles de litigiosidad estatal heterocompositiva ${ }^{146}$, a los que la oralidad y autonomía de partes no resulta, en absoluto, extraña ${ }^{147}$, pues, en realidad, la diferencia entre su instauración en estos medios y los adscritos al common

\footnotetext{
140 Chase (2005), p. 26.

141 Chase (2005), p. 76.

142 ZUCKERMAN (2006), p. 143.

143 DAMASKa (2000), p. 86.

144 Hunton y Williams (2015).

145 VAN RheE (2005), p. 30.

146 Barona (2011), p. 193.

147 VAN RheE (2005), p. 24.
} 
law estadounidense e inglés, a lo menos en la etapa que a esta institución interesa, radica casi por completo en la relevancia del rol que la ley le entrega al juez y en la unidad del procedimiento de revelación o su dispersión en todo el proceso ${ }^{148}$, preocupación central esta desde hace ya tiempo presente en el modelo inglés del procedimiento civil ${ }^{149-150}$ y que, como se examinó más arriba, ha sido recogida también por las FRCP en los EE.UU. en su anunciada reforma de $2015^{151}$.

Son múltiples, por ende, los motivos que Ilevan a concluir que la incorporación de algún tipo de ERTEP, consonante con los ya mencionados principios de cooperación entre las partes bajo dirección judicial, hoy punto central en la evolución de los procesos civiles europeos e incluso ingleses ${ }^{152}$, en definitiva, no encuentra puntos de conflicto evidentes con un diseño adversarial del proceso civil, aun de inspiración continental, dejando a salvo, por cierto, la posibilidad de debatir su extensión, profundidad y envergadura, las que deben analizarse a la luz de una inspiración claramente orientada en nociones de proporcionalidad racional, hoy fuertemente reforzadas en los ordenamientos en que se originan aquellas ${ }^{153}$ y que han sido objeto de este estudio, modulándolas, como se dijo, a partir de los objetivos que el propio litigio trace para cada caso en particular ${ }^{154}$.

\subsection{La pesada carga de la cuestión cultural}

Resta por dilucidar, por tanto, cómo se supera la pesada carga que representa la herencia jurídico-cultural del civil law o derecho continental en Chile, propia de un modelo jerárquico que reclama para sí, como se consignó antes, una suerte de exclusividad oficial en la respuesta a los interesados en la solución del conflicto ${ }^{155}$, y que, por cierto, puede llegar a apreciar en este tipo de instituciones una hibridación inaceptable que, lejos de representar un aporte a la inspiración adversarial del proceso que asume modelos de

\footnotetext{
148 SUBRIN (2002), p. 301.

149 VAN RHEE (2005), p. 36.

150 ANDREWS (2012), p. 254.

151 Hunton y Williams (2015).

152 VAN RHEE (2005), p. 38.

153 Hunton y Williams (2015).

154 DAMASKA (2000), p. 99.

155 DAMASKA (2000), p. 99.
} 
oralidad, les distorsione gravemente al pretender echar mano a instituciones ajenas a los fines que se ha planteado el diseño de las reformas ${ }^{156}$.

¿Conlleva la hibridación, desde esta perspectiva, una carga siempre negativa? No parece ser así, y tanto la dogmática como la apreciación comparada de sistemas de reforma judicial parecen demostrarlo ${ }^{157}$.

Simples analogías no son, en este sentido, suficientes: ellas suelen disfrazar acuerdos que no pasan de ser simples logros retóricos, y así lo ha demostrado la dogmática más autorizada158. Ello ocurre así por cuanto: "Las formas de solución de conflictos son en gran parte un reflejo de la cultura en la cual se integran; no son un sistema autónomo fundamentalmente producto de expertos y especialistas aislados ${ }^{\prime 159}$.

Con todo, es necesario consignar acá que los extremos se tocan en esta materia: no es irrelevante el hecho de que una serie de ordenamientos importantes, dispersos por el globo, desde Japón hasta Alemania, como se pasó revista antes, hayan adoptado algún tipo de instancia de discovery, entregando mayor o menor relevancia al papel de dirección que debe adoptar el juez, por cierto.

Sin embargo, de lo ya expresado y en paralelo con ello, no puede dejar de observarse que las conductas forenses de los operadores pueden dar a reglas análogas o al menos de similar inspiración una aplicación enteramente diversa, al extremo de llevarlas a la inoperancia. Considérese, por ejemplo, la experiencia italiana, en que a pesar de haberse normado a favor de la inserción de etapas de mediación previa del conflicto jurídicamente relevante y que, de hecho, suele representar un medio importante para revelar evidencia en instancia prejudicial cuando no se cuenta con un discovery en forma ${ }^{160}$, la jurisprudencia ha admitido que el interesado recurra, sin más, a la justicia estatal, sin que siquiera ello dé motivo suficiente para suspender sus procedimientos en aras de completar el mencionado proceso y ni tan siquiera otorgue el derecho a demandar una indemnización de perjuicios por la inobservancia a lo pactado si ello había sido así161.

Frente a dicho ejemplo, brilla con luz propia el caso japonés, en que la estricta observancia a las reglas de revelación prejudicial de evidencia se

\footnotetext{
156 Montero (2014).

157 TWINING (1993), p. 390.

158 Damaska (2000), p. 10.

159 Chase (2005), p. 21.

160 Giannini (2014), p. 159.

161 VIGORITI (2008).
} 
encuentra entregada a la iniciativa de cooperación libre de las partes, sin apremios judiciales, a pesar de lo cual (o tal vez debido a lo cual), muchos observadores del sistema han detectado que una cantidad relevante de documentos se revelan en esta etapa del proceso ${ }^{162}$.

Y sin embargo, en ambos ordenamientos existe una etapa de revelación temprana funcional expresa o al menos implícita operativa a pesar de que, en casos extremos, en ciertos ordenamientos sea mirado con especial recelo e incluso como una amenaza para la soberanía nacional su ejercicio por parte de los operadores angloamericanos, al punto de sujetar la concesión de visas de trabajo a los abogados norteamericanos a la declaración bajo juramento de que no perseguirán con ello obtener declaraciones en un proceso de discovery ${ }^{163}$, aunque ello pueda responder, en realidad, a un celo extraordinario en la preservación de las prerrogativas de la judicatura ${ }^{164}$, el que tampoco se encuentra del todo ausente, por demás, en nuestro medio que, sin embargo, no cuenta con experiencias propiamente asimilables a las ya descritas ${ }^{165}$.

La consideración cultural resulta ser paradigmática precisamente allí donde más extensión tienen las instituciones del discovery: en los Estados Unidos de Norteamérica se presentan consideraciones de todo orden que se encuentran prácticamente ausentes en otras latitudes y que muchas veces resultan incluso exorbitantes a aprensiones estrictamente jurídicas, ello por cuanto: "... un americano es incapaz de manejar un caso sin la investigación prejudicial y la declaración preprocesal. La investigación es su ducha y la declaración, su desayuno"1166.

El extremo nivel de litigiosidad no es ajeno, tampoco, a la cultura norteamericana: ya en la época en que nacía la república estadounidense, Alexis de Tocqueville podía declarar, en su celebérrima obra Democracy in America que: "Difícilmente hay cuestiones políticamente relevantes en los Estados

\footnotetext{
162 SUBRIN (2002), p. 303.

163 Subrin (2002), p. 307, invocando ciertas fuentes inglesas y canadienses que ven al discovery norteamericano como una mera expedición de pesca.

164 DamaSKA (2000), p. 119.

165 Es cierto que nuestros ordenamientos reformados contemplan audiencias preparatorias de ofrecimiento de prueba, también conocidas como de preparación de juicio oral, pero no lo es menos que ellas son esencialmente diversas del modelo en estudio, por una parte, por cuanto las ERTEP no tienen por objeto ofrecer prueba para un juicio y, por otra, tampoco se insertan en el desarrollo del juicio, sino que antes de arribar de lleno a este, al extremo de permitir modelar en armonía con sus resultados las pretensiones de las partes.
}

166 Chase (2005), p. 90. 
Unidos que, tarde o temprano, no se transforme en asuntos judiciales ${ }^{\prime 167}$, amplia judicialización de las cuestiones políticas más relevantes que ha marcado profundamente la manera como el common law se ha desarrollado en dicho ordenamiento ${ }^{168}$, ello a pesar de tratarse de un fenómeno que ha sido severamente cuestionado desde las más autorizadas tribunas legales, las cuales, de hecho, creen ver en una restricción al discovery una potente señal a favor de una litigiosidad desbordada ${ }^{169}$.

Por otra parte, la arraigada desconfianza hacia la intervención de la autoridad en todo género de asuntos ${ }^{170}$, particularmente cuando esta se encuentra concentrada en instituciones monolíticas, ha tenido, también, un trasunto en el diseño de sus instituciones jurisdiccionales ${ }^{171}$ y concretamente en aquellas que ocupan a estas reflexiones ${ }^{172}$, motivando un activísimo rol de las partes por sobre el del juez civil que ha mantenido, aun contando con facultades importantes de intervención en la dirección del proceso, un rol más bien pasivo, al extremo de dar lugar a un consenso entre los litigantes acerca de la necesidad de contar con un juez más activo, especialmente en el proceso del discovery ${ }^{173}$, evolución que encuentra amplio reconocimiento y sustento en la más autorizada doctrina en ese medio ${ }^{174}$ y que explica, por demás, la casi irrestricta intervención que a las partes les reconoce la ley en este proceso ${ }^{175}$.

Este conjunto de razones explica que las ERTEP se encuentren imbricadas de tal manera con el proceso civil estadounidense, que los legisladores ya en la década de los 30 del siglo XX (época de la codificación de las FRCP) hayan afirmado, sin vacilaciones, que mientras más amplitud se le diera al discovery, mejores serían los resultados que ello reportaría al proceso civil: "El

\footnotetext{
167 SUBRIN (2002), p. 310.

${ }^{168}$ CHASE (2005), p. 78. Este autor vincula, de hecho, cuatro características fundamentales del proceso civil con las características culturales estadounidenses: (a) El jurado civil; (b) el discovery; (c) la pasividad del juez y (d) la elección de los peritos por las partes.

$169 \mathrm{HENCH}$ (1994), p. 198, invocando en tal sentido a un presidente de la Corte Suprema (Warren Burger) y a un rector de Harvard (Derrick Bok).

170 No muy diversa de aquella que marcó el diseño de los sistemas procesales en el Estado liberal del siglo XIX. Así en Montero (2014), p. 26.

171 NiemeYer (1998), p. 520.

172 Pero, por supuesto, no exclusivamente estas, pues otras pueden ser tenidas como aún más representativas del fenómeno en cuestión, como el juzgamiento civil por jurados, afín a la noción de "...idea social de participación popular en la justicia y resolución entre iguales...". CHASE (2005), p. 2.

173 Niemeyer (1998), p. 523.

174 Por todos: Damaska (2000), p. 160.

175 Damaska (2000), p. 369.
} 
conocimiento recíproco de todos los hechos relevantes recogidos por ambas partes resulta esencial para una litigación adecuada"176. Discovery y litigación civil representan en dicho ordenamiento, por lo tanto, como se dijo, una unidad completamente indisoluble, por mucho que las tendencias reformistas apunten a confinar el proceso en límites de proporcionalidad y racionalidad ${ }^{177}$.

La litigación civil en los Estados Unidos de Norteamérica significa, pues, discovery gobernado por los abogados de las partes y, de hecho, no deja de sorprender a los operadores de ese sistema, que gran parte de los sistemas comparados haya podido funcionar de manera exitosa sin contar con este tipo de instituciones, o por lo menos, sin la amplitud con que son concebidas en el ordenamiento estadounidense ${ }^{178}$, amplitud que se obtiene, por cierto, a costa de las facultades del juez que se ve constreñido a su tradicional rol de adjudicador como exclusivo, al punto que se ha llegado a afirmar que la totalidad de las actividades del Estado están subordinadas a la resolución de la disputa y que, de hecho, la rama judicial es la única rama del Estado ${ }^{179}$.

3.4. Establecido que ha sido que: (a) Oficialmente, entre nosotros, los procedimientos propuestos para modernizar la justicia civil contemplan estructuras claramente adversariales, con especial atención hacia la oralidad como elemento funcional a los atributos de la moderna administración de justicia; (b) Que este tipo de procesos demandan, de manera preponderante, un activo rol de las partes litigantes inspiradas en nociones de buena fe, transparencia, igualdad de armas y colaboración recíproca y para con el tribunal y que, (c) Finalmente, los proyectos en curso otorgan a los SARC un lugar de particular relevancia como salida alternativa (y no secundaria, sino que más bien "adecuada" al conflicto $)^{180}$ ante el diferendo jurídicamente relevante, resulta preciso concluir que la adopción de alguna de las formas de ERTEP se

\footnotetext{
176 SUBRIN (2002), p. 300.

177 NiemeYer (1998), p. 520. Este autor, quien desde su rol de juez de Corte del Cuarto Distrito Federal presidió el Comité Asesor de Reglas del Procedimiento Civil que derivó en las reformas a las FRCP en esta materia, sostiene en tal sentido que: "La completa revelación a través del discovery es un elemento esencial y aceptado en todo proceso de resolución de disputas". Esta afirmación, tomada de la jurisprudencia de la Corte Suprema en el leading case "Hickman v. Taylor" de 1947 se ha descrito, con todo, como responsable de "abrir la Caja de Pandora que representa el discovery abusivo" por la amplitud de sus términos. Así en HeNCH (1994), p. 186.
}

178 SUBRIN (2002), p. 301: "El escepticismo (de los operadores norteamericanos hacia los esfuerzos por eliminar del discovery sus aspectos negativos) se ve ensalzado cuando se analizan las instituciones de discovery en el resto del mundo, donde la civilización parece haber sobrevivido bastante bien sin el discovery 'a la americana'".

179 DAMASKA (2000), p. 132.

180 BARONA (2011), p. 194. 
impone de manera casi ineludible: no parece posible ni aconsejable prescindir de una herramienta que ha comprobado reportar resultados favorables a puntales tan centrales a nuestros procedimientos de modernización de la justicia como los ya analizados, y así incluso lo han resuelto autores que beben de inspiraciones continentales tan poderosas como la nuestra ${ }^{181}$.

Es fundamental, pues, diseñar herramientas que permitan una inserción sencilla, no traumática, de este tipo de instituciones que, a tales efectos, pueden recurrir (sin que ello implique replicar, desde luego) a experiencias ya conocidas entre nosotros que, de manera incipiente, representan un avance hacia la revelación de evidencia pertinente en etapas tempranas del conflicto.

Concretamente, en tal sentido, resulta forzoso recordar la obligación de presentar los documentos fundantes de la demanda junto con esta, desaparecida con la reforma de la ley $N^{0} 18.705$, de $1988^{182}$. Otra experiencia interesante, cuyos efectos conviene sondear, es aquella que proviene de la reforma a la justicia tributaria y, concretamente, al inciso undécimo del artículo 132 del Código Tributario, conocido precisamente tanto por los operadores como por la doctrina como el "minidiscovery tributario". En virtud de esta regla, la parte tiene prohibido valerse de aquella prueba documental que, requerida por parte de la autoridad tributaria en etapas administrativas de fiscalización previa, no haya sido aportada sin fundamentos suficientes que expliquen la reticencia. Son estas, sin embargo, experiencias acotadas y dispersas, de reducido alcance, que claramente no resultan comparables con el discovery amplio propiamente dicho, pero que tienen un valor potencial de arrojar luz sobre el eventual efecto que su aplicación tendría entre nosotros.

Puestos en este escenario, no parece impropio recordar que los ordenamientos comparados, y en particular el estadounidense, también se encuentran

181 Giannini (2014), p. 158.

182 Disponía el antiguo artículo 252 del Código de Procedimiento Civil: "El actor deberá presentar con su demanda los instrumentos en que la funde. Si no se diere cumplimiento a esta disposición, exigiéndolo el demandado, los instrumentos que se presentaren después sólo se tomarán en consideración si el demandado los hiciere también valer en apoyo de su defensa, o si se justifica o aparece de manifiesto que no pudieron ser presentados antes, o si se refieren a hechos nuevos alegados en el juicio con posterioridad a la demanda. En estos casos, si la presentación se hiciere después de expirado el término probatorio o no hubiere habido lugar a este trámite, podrá el tribunal, a petición del demandado, abrir un término especial con relación a los nuevos instrumentos acompañados y se tramitará esta gestión en pieza separada, según las reglas establecidas para los incidentes, suspendiéndose el juicio principal sólo en el momento de dictar sentencia definitiva, si el incidente no hubiere termina$d o^{\prime \prime}$. La norma provenía de una propuesta en el proyecto de don José Bernardo Lira, incorporándose la referencia a la exigencia de parte durante su discusión. Resulta interesante comprobar que una institución notablemente análoga ha sido introducida recientemente en las reformas al Procedimiento Civil japonés: Honma (2008), p. 254. 
embarcados en procesos de modernización de la justicia que han afectado directamente este tipo de instituciones, con la finalidad de eliminar de ellas los elementos que representen externalidades contrarias a las finalidades del proceso, principalmente en términos de costos y dilaciones indebidas ${ }^{183}$, concebidas globalmente como el "discovery abusivo"184 (las conocidas "expediciones de pesca" emprendidas por demandantes que, carentes de todo sustento, esperan encontrarlo a través de estas) sin que ello implique sacrificar, claro está, una revelación de evidencia lo más profunda posible ${ }^{185}$.

En este contexto, y teniendo presente que el objetivo propuesto es el lograr una inserción gradual de la institución que evite experiencias traumáticas a los operadores del sistema y teniendo en vista, además, que como ampliamente se expuso antes, el rol que las partes litigantes deben jugar en ellas es crucial, parece de utilidad recordar el ya mencionado plan de discovery en tres niveles o capas (conocido en los EE.UU. como el "Plan Napolitano"), pues presenta la ventaja de dejar a disposición de los litigantes herramientas para regular la intensidad de la revelación de evidencia que la adecuada defensa de sus derechos aconseje $e^{186}$ y que no siempre requiere la presencia judicial activa.

Un primer nivel, básico o mínimo, es legalmente obligatorio, pero de un alcance más bien acotado y que puede limitarse a ciertos medios de sustento de las pretensiones. Un segundo nivel, que requiere la participación activa de los abogados de las partes (que bien pueden no requerirlo del todo), cubre ya todo el material de convicción que estas estimen preciso conocer para una adecuada defensa de su caso o solo la parte que ellos tengan por relevantes, siempre merced al acuerdo de los litigantes. Un tercer nivel, que puede denominarse como de "discovery hostil", requerirá ya la activa dirección del Juez, el que intervendrá sólo a falta de acuerdo de las partes en la etapa anterior, con la finalidad de aprobar las pretensiones de revelación que los litigantes manifiesten y fijar un itinerario definido que impida una prolongación indebida de esta etapa. Con todo, las partes siempre podrán sencillamente no recurrir a las etapas más avanzadas del discovery, respetando su derecho a diseñar libremente su estrategia procesal.

\footnotetext{
183 NiemeYer (1998), p. 517.

184 SUBRIN (2002), p. 309.

185 Cierto es, sin embargo, que los procesos de reforma han tenido por objeto, además, uniformar las reglas del discovery y procurar un rol más activo del juez en la dirección del mismo, finalidades obviamente ajenas a nuestros ordenamientos y que es necesario discernir cuidadosamente, identificando las medidas que resulten estrictamente funcionales a dichos fines.
}

186 NiemeYer (1998), p. 524. 
Este esquema presenta, además, la ventaja de ofrecer a las partes diversas salidas SARC en los distintos niveles del discovery, consonantes con la profundidad y tipo de información que hayan obtenido en ellos y que puede representar, de hecho, un incentivo muy importante para recurrir a aquellos, conformando con ello un verdadero "tribunal multipuertas" que, a la vez, observa una deferencia relevante por la autonomía de la voluntad de los litigantes ${ }^{187}$.

No representa esta, desde luego, una alternativa que por sí sola solucione la totalidad de los problemas de orden verdaderamente cultural que la inserción de este tipo de instituciones pueda presentar entre nosotros, pero lo cierto es que, por una parte, permite acotar sus efectos, nocivos si es del caso, a un área más bien restringida de la litigación en tanto que, por otra, abre la posibilidad de dar un punto de partida a la aplicación de las instancias de discovery y disclosure que, por el cúmulo de motivos ya expresados, el proceso de modernización de la justicia civil imperiosamente requiere, pues no parece aconsejable dar inicio a la aplicación de procedimientos de naturaleza adversarial y oral sin que previamente se considere un incentivo relevante a la aplicación de SARC del más amplio espectro y alcance (incluso heterónomas), que impida el descenso en la calidad de la respuesta judicial que el aparato judicial representa ${ }^{188}$ al ofrecer, en sustitución de esta, salidas modeladas a las necesidades del caso en concreto y en paralelo, en lo que dice relación con los efectos al interior del proceso, evite asimetrías, sorpresas procesales y la desigualdad de armas que solo las ERTEP pueden impedir.

\section{Algunas notas a manera de conclusión}

4.1. La experiencia comparada en los Estados Unidos y en Inglaterra, en menor medida, en materia de las instancias de revelación temprana de evidencia denominadas discovery y disclosure demuestran que, en definitiva, los beneficios que representa su inserción al interior del proceso civil aventajan largamente las dificultades y contratiempos que su aplicación abusiva pueda acarrear, superando los reparos procedimentales, pecuniarios y aun culturales que se puedan atribuir a dicho proceso, tanto en su inserción en el medio nacional como en el propio desarrollo de aquellas en este.

4.2. A la hora de considerar la extrapolación de estas instituciones a un sistema jurídico de corte continental como el chileno, se impone constatar que un buen número de los problemas que acarrea el uso desmedido o abusivo de

187 Mullerat (2002), p. 51.

188 Barona (2011), p. 186. 
estas instituciones, principalmente en términos de costos y demoras, pueden evitarse o al menos mitigarse de manera importante mediante la adopción de múltiples medidas que, otorgando al juez un rol activo en la dirección del proceso (managerial judge), no extraño a las nociones que imperan en nuestros procesos reformados, incluso en estas etapas tempranas permiten confinar, como se dijo, los efectos adversos que ellos puedan presentar.

La experiencia en la fuente de estas instituciones (IOS EE.UU., principalmente) demuestra, precisamente, un progresivo realce en las facultades concedidas, en este sentido, a la instancia judicial, reclamada por amplios sectores del foro y la magistratura que entienden que la concesión de facultades excesivamente amplias en las partes termina por poner en realce las externalidades negativas del discovery en términos de tiempos, costos y asimetrías indeseadas entre las mismas.

4.3. Las instituciones de revelación temprana de evidencia se insertan de mejor manera en proceso de corte adversarial, en que las partes ocupan un rol preponderante definiendo el objeto de la controversia y el material probatorio que requerirán para su defensa. Ello no impide otorgar en paralelo, como lo hacen nuestros procesos reformados, un rol activo al juez, en la preservación de una proporcionalidad del discovery en relación con los objetivos del litigio en particular, ello por cuanto es en aquellos procesos en que más se requiere de un desempeño colaborativo, de buena fe y equitativo de las partes en conflicto que asegure, además, el éxito en la aplicación acotada de la institución, precaviendo precisamente el quebrantamiento de las mencionadas nociones.

4.4. La adopción de instancias de discovery importa, además, como una valiosa externalidad ampliamente comprobada en los ordenamientos en estudio, favorable a las finalidades declaradas de nuestros procesos de modernización de la justicia, si bien no desarrolladas aún, consistentes en la promoción pública de los SARC, cuyo uso intensivo es privilegiado aun a nivel de principios por los proyectos de reforma en referencia. No parece propio ni aconsejable, por lo tanto, desdeñar su aplicación por el solo hecho de estimarse extraña a nuestra cultura jurídica, pues se trata, desde esta perspectiva, de una herramienta ambivalente que es preciso evaluar.

4.5. La propia experiencia comparada y, en particular, la que proviene del common law estadounidense, ofrece un número de herramientas y técnicas que permiten superar o al menos mantener en un ámbito muy acotado los eventuales bemoles o externalidades negativas que pueda representar la aplicación indiscriminada de este tipo de instituciones. Amén de la concesión de facultades gradualmente más relevantes al juez, y en consonancia con 
ellas, presenta particular interés la propuesta diseñada en torno al así llamado discovery en tres fases, niveles o capas.

Esta última técnica permite una aplicación gradual y proporcionada del discovery, entregando a las partes en conflicto herramientas que les permiten definir cuán lejos desean llegar en el proceso de revelación de evidencia y, con ello, sondear de manera plenamente informada la posibilidad de recurrir a medios alternativos adecuados para la resolución del conflicto, objetivo este declaradamente valorado por las iniciativas de reforma en curso en nuestro medio y que, en definitiva, se privilegiará de mejor forma por medio del recurso a esta herramienta.

\section{Bibliografía CitADA}

\section{Publicaciones Científicas}

Andrews, Neil (2011): Justicia civil inglesa. Proceso civil y otras formas de resolución de controversias (Bogotá, Ed. Temis).

ANDREWS, Neil (2012): "La combinación de la administración pública y privada de la justicia civil", en: Revista de Derecho, P. Univ. Católica de Valparaíso (No 39), pp. 253-289.

Barona, Silvia (2005): "Fomento de las ADR en España", en: Revista Sequencia, (No 51), pp. 169-201.

BARONA, Silvia (2010): El movimiento de las ADR en el derecho comparado (Madrid, La Ley).

Barona, Silvia (2011): "Las ADR en la justicia del siglo XXI, en especial la mediación", en: Revista de Derecho, U. Católica del Norte (Año 18, №1), pp. 185-211.

BoETSCH, Cristián (2011): La buena fe contractual (Santiago, Editorial Jurídica de Chile).

CARRETA, Francesco (2013): La coherencia en el proceso civil. Imperativo conductual y decisional desde la buena fe (Santiago, LegalPublishing Chile).

Carvajal, Patricio-Ignacio (2011): "Artículo 706 del Código Civil chileno: Crítica como pretendido núcleo textual del principio de buena fe", en: A.A.V.V., Estudios de Derecho Civil. Parte General, Acto Jurídico y Derecho de Bienes (Santiago, AbeledoPerrot-LegalPublishing Chile), tomo I, pp. 31-45.

CHASE, Óscar (2005): Derecho, cultura y ritual. Sistemas de resolución de controversias en un contexto intercultural (Barcelona, Marcial Pons).

Crump, David; Dorsaneo, William; Perschbacher, Rex y Basset, Debra (2003): Cases and Material on Civil Procedure (Newark, LexisNexis). 
DAMASKA, Mirjan (2000): Las caras de la justicia y el poder del Estado (Santiago, Ed. Jurídica de Chile).

DuCE, Mauricio; Marín, Felipe y Riego, Cristián (2008): “Reforma a los procesos civiles orales: Consideraciones desde el debido proceso y la calidad de la información", en: CABezón, Andrea; ArAnedA, Sandra (editores), Justicia Civil: Perspectivas para una reforma en América Latina (Santiago, Centro de Estudios de Justicia de las Américas, CEJA), pp. 13-94.

EINHAUS, Stefan (2008): "The introductory phase and the procedural contract - England and Wales", en: Carpi, Federico y Ortells, Manuel (editores), Oralidad y escritura en un proceso civil eficiente (Valencia, Universidad de Valencia), tomo I, pp. 241-250.

Farmer, Amy y Pecorino, Paul (2013): "Discovery and Disclosure with Asymmetric Information and Endogenous Expenditure at Trial", en: The Journal of Legal Studies (Vol. 42, № 1), pp. 223-247.

GIANNINI, Leandro (2014): "Experiencia argentina en la mediación obligatoria", en: La Ley (5 de febrero de 2014), pp. 1-7.

GIlsAnz, Javier (2010): The global law collection. El proceso civil estadounidense: la tutela judicial cautelar (Pamplona, Thomson Reuters).

GlenN, Hazel; FenN, Paul et al. (2007): Twisting arms: court referred and court linked mediation under judicial pressure (Londres, GSR).

Hazard, Geoffrey y Taruffo, Michele (2006): The global law collection. La justicia civil en los Estados Unidos (Navarra, Thomson Reuters).

HeNCH, Virgina (1994): "Mandatory disclosure and equal access to justice: The 1993 Federal Discovery Rules Amendments and the just, speedy and inexpensive determination of every action", en: Temple Law Review (Vol. 67), pp. 18-240.

Honma, Manabu (2008): "The preliminary phase and the trial agreement in Japan", en: CARPI, Federico y Ortells, Manuel (editores), Oralidad y escritura en un proceso civil eficiente (Valencia, Universidad de Valencia), pp. 251-262.

Hunton y Williams, LLP (2015): "New federal rules aim to promote proportionality in discovery". Disponible en: http://www.lexology.com/library/detail. aspx?g=ab96e5a6-3dab-4e0b-9877 36649baadde [visitado el 15/12/2015].

LEIPOLD, Dieter (2008): "Elementos orales y escritos en la fase introductoria del proceso civil", en: CarpI, Federico y Ortells, Manuel (editores), Oralidad y escritura en un proceso civil eficiente (Valencia, Ed. Universidad de Valencia), tomo I, pp. 79-92. 
Montero, Juan (2014): La paradoja procesal del siglo XXI (Valencia, Ed. Tirant lo Blanch).

Mullerat, Ramón (2002): "La justicia alternativa en los Estados Unidos de Norteamérica", en: Anuario de Justicia Alternativa ( $\mathrm{N}^{\circ} 3$ ), pp. 47-73.

Niemeyer, Paul (1998): "Here We Go Again: Are The Federal Discovery Rules Really in Need of Amendment?", en: Boston College Law Review (Vol. 39), pp. 517-524.

Oberen, Walter (1987): "Trial by Ambush or Avalanche-The Discovery Debacle", en: Journal of Dispute Resolution (Vol. 1987), pp. 1-10.

Palomo, Diego y Delgado, Jordi (2016): "Justicia Civil y Privada: Términos para un adecuado entendimiento. Una mirada desde Chile y sus procesos de reforma", en: Civil Procedure Law Review (Vol. 7, № 2), pp. 86-134.

Poder Judicial (2015): "Planificación estratégica del Poder Judicial. Plan 20152020". Disponible en: http://www.pjud.cl/documents/10179/104862/Pla nificaci\%C3\%B3n+Estrat\%C3\%A9gica+20152020++\%28Versi\%C3\%B3 n+extendida\%29.pdf/15b039c1-97f5-46ce-99ca-3ab2cbef2ee0 [visitado el 28/02/2017].

RESNIK, Judith (1986): "Failing Faith: Adjudicatory Procedure in Decline", en: U. of Chicago Law Review (Vol. 53, N² 2), pp. 494-560.

Rutgers, Robert y Rutgers, Jacobien (2006): "Reform of the Code of Civil Procedure in the Netherlands", en: VARANO y TROCKER (Editor), The reforms of civil procedure in comparative perspective. An international conference dedicated to Mauro Cappelletti, Florence, 12-13 December 2003 (Giachipelli, Torino), pp. 131-141.

Segura, Francisco (2011): "Buena fe, un aspecto de tensión entre los sistemas jurídicos", en: A.A.V.V., Estudios de Derecho Civil. Parte General, Acto Jurídico y Derecho de Bienes (Santiago, AbeledoPerrot - LegalPublishing Chile), pp. 499-510.

Subrin N., Stephan (2002): "Discovery in Global Perspective: Are we nuts?", en: De Paul Law Review (Vol. 52), pp. 299-319.

Summers, Clyde (2011): "Alternative dispute resolution in United States", en: Revista Latinoamericana de Derecho Social, UNAM (No 13), pp. 25-35.

TARUFFO, Michele (2008): El proceso adversarial en la experiencia americana (Bogotá, Editorial Temis).

TwINING, William (1993): "Alternative to What? Theories of Litigation, Procedure and Dispute Settlement in Anglo-American Jurisprudence: Some Neglected Classics", en: The Modern Law Review (MRL56:3, May), pp. 380-392. 
Unidad de Mediación Consejo de Defensa del Estado (2011): "Mediación y desjudicialización en el Consejo de Defensa del Estado (CDE)". Disponible en: http://www.cde.cl/mediacion/wp-content/uploads/sites/16/2016/01/ ESTUDIO-DESJUDICIALIZACION-nov-2011.pdf [visitado el 28/02/2017].

Van Rhee, Remco (2011): "Tradiciones europeas en el procedimiento civil: Una introducción", en: Revista de Estudios de la Justicia ( $N^{\circ} 15$ ).

VIAL, Jorge (2006): "Reforma Procesal Civil: Una mirada desde el Derecho norteamericano", en: SiLVA, José; García, José y Leturia, Francisco (editores), Justicia civil y comercial: Una reforma pendiente. Bases para el diseño de la reforma procesal civil (Santiago, Fundación Libertad y Desarrollo, P. Universidad Católica de Chile, Universidad Autónoma de Madrid), pp. 703-720.

Vigoriti, Vicenzo (2008): "Access to Justice, ADR, Perspectives", en: Anuario de Justicia Alternativa ( $N^{\circ}$ 9), pp. 121-131.

Walter, Gerhard (2006): "The German Civil Procedure Reform Act: Much Ado Abought Nothing?", en: VARANO y TROCKER (editor), The reforms of civil procedure in comparative perspective. An international conference dedicated to Mauro Cappelletti, Florence, 12-13 December 2003 (Guiachipelli, Torino), pp. 67-88.

Willging, Thomas; Stienstra, Donna y Shapard, John (1998): "An empirical study of discovery and disclosure practice under the 1993 Federal Rule Amendments", en: Boston College Law Review (Vol. 39), pp. 525-596.

Zuckerman, Adrian A.S. (2006): "Court Control and Party Compliance - The Quest for Effective Litigation Management", en: VARANO Y TROCKER (editor), The reforms of civil procedure in comparative perspective. An international conference dedicated to Mauro Cappelletti, Florence, 12-13 December 2003 (Guiachipelli, Torino), pp. 143-159.

\section{CUERPOS NORMATIVOS CITADOS}

- Federal Rules of Civil Procedure.

- Código de Procedimiento Civil de la República de Chile.

- Proyecto de Código Procesal Civil chileno.

- Código Tributario de la República de Chile.

- Código del Trabajo de la República de Chile.

- Código Procesal Penal de la República de Chile.

- Ley No 19.966 de la República de Chile. 